\title{
Uncovered interest rate parity and the term structure
}

\author{
Geert Bekaert $^{\mathrm{a}, *}$, Min Wei $^{\mathrm{b}}$, Yuhang Xing ${ }^{\mathrm{c}}$ \\ ${ }^{a}$ Columbia Business School, 808 Uris Hall, 3022 Broadway, New York, NY 10027, USA \\ ${ }^{\mathrm{b}}$ Board of Governors of the Federal Reserve, Division of Monetary Affairs, Washington, DC 20551, USA \\ ${ }^{c}$ Jones Graduate School of Management, Rice University, Room 230, MS531, 6100 Main Street,
} Houston, TX 77005, USA

\begin{abstract}
This paper examines uncovered interest rate parity (UIRP) and the expectations hypotheses of the term structure (EHTS) at both short and long horizons. The statistical evidence against UIRP is mixed and is currency- not horizon-dependent. Economically, the deviations from UIRP are less pronounced than previously documented. The evidence against the EHTS is statistically more uniform, but, economically, actual spreads and theoretical spreads (spreads constructed under the null of the EHTS) do not behave very differently, especially at long horizons. Partly because of this, the deviations from the EHTS only play a minor role in explaining deviations from UIRP at long horizons.
\end{abstract}

(C) 2007 Elsevier Ltd. All rights reserved.

JEL classification: E4; F3; C5

Keywords: Foreign exchange; Term structure; Uncovered interest rate parity; Expectations hypotheses; Unbiasedness hypothesis

\section{Introduction}

Uncovered interest rate parity (UIRP) predicts that high yield currencies should be expected to depreciate. It also predicts that, ceteris paribus, a real interest rate increase should appreciate the currency. UIRP is one of the cornerstones of international finance, constituting an important building block of most important exchange rate determination theories such as the monetary

\footnotetext{
* Corresponding author. Tel.: +1 212854 9156; fax: +1 2126628474 .

E-mail addresses: gb241@columbia.edu (G. Bekaert), min.wei@frb.gov (M. Wei), yxing@rice.edu (Y. Xing).
} 
exchange rate model, Dornbusch's (1976) overshooting model or Krugman's (1991) target zone model and dominating the discussion on exchange rate determination in most international textbooks. Nevertheless, there appears to be overwhelming empirical evidence against UIRP, at least at frequencies less than 1 year (see Bekaert and Hodrick, 1993; Engel, 1996; Froot and Thaler, 1990; Mark and Wu, 1998). Given that this empirical evidence has not stopped theorists from relying on UIRP, it is fortunate that recent evidence is more favorable: Bekaert and Hodrick (2001) and Baillie and Bollerslev (2000) argue that doubtful statistical inference may have contributed to the strong rejections of UIRP at higher frequencies whereas Chinn and Meredith (2004) marshal evidence that UIRP holds much better at long horizons. Chaboud and Wright (2005) investigate overnight exchange rate movements and interest-rate differentials and also find support for UIRP.

It seems rather difficult to find a coherent story to explain all these results. Short-term deviations of UIRP may occur while long-horizon UIRP holds (see Froot and Thaler, 1990), if inefficient markets or short-term market frictions prevent an immediate complete response of the exchange rate to an interest rate change.

However, both the theoretical and the empirical results seem puzzling on second thought. First, it is hard to reconcile the high frequency Chaboud and Wright (2005) results, the standard rejections at weekly or monthly frequencies and the long-term evidence from this frictions-perspective. In fact, the presence of speculative capital of various proprietary desks in foreign exchange markets attempting to exploit deviations from UIRP (see Green, 1992 for an illustration) suggests that it might be the long-term relation rather than the short-term relation that is affected by market frictions, since it is unlikely that these trading desks will keep capital tied up in such long-term contracts. Second, by construction, if UIRP holds in the short run, it should hold in the long run as long as the expectations hypotheses of the term structure of interest rates (EHTS) holds; that is, as long as the long rate equals the average expected future short rate over the life of the bond. It seems unlikely that the short-term deviations from UIRP would exactly offset the long-term deviations from the EHTS to make UIRP hold in the long run. In alternative models based on risk, a time-varying risk premium separates expected exchange rate changes from the interest differential and a time-varying term premium separates the long-term interest rate from expected future short rates. Consequently, these risk premiums would be driven by the same fundamentals and deviations from UIRP and the EHTS should be visible at both long and short horizons. Such a story is potentially consistent with the Chaboud and Wright (2005) results as they focus on observations where exchange risk is minimal (but interest is still paid) and the risk premium may vanish.

It is therefore worthwhile to re-examine UIRP and the EHTS simultaneously at long and short horizons. To do so, our main tool of analysis will be a vector autoregression (VAR) on exchange rate changes, interest rates and term spreads, drawing data from three countries: the US, the UK and Germany. The VAR not only allows us to disentangle the various hypotheses in a unified framework, it also makes it easy to conduct more powerful joint tests across both short and long horizons. Clarida and Taylor (1997) and Clarida et al. (2003) show that forward premiums of different maturities are helpful in forecasting exchange rates. We also include long-term spreads (of a 5-year maturity) in the VAR. Apart from the statistical significance, we also examine the economic significance of potential deviations from UIRP and the EHTS. Many policy makers conduct policy experiments imposing the EHTS for example (see Evans, 1998; Bernanke et al., 1997). If the EHTS does not hold statistically, but the spread as predicted by the EHTS and the actual spread are very highly correlated, 
assuming the EHTS in a policy analysis may be acceptable. Our framework allows us to investigate the economic significance of imposing different hypotheses.

Our main findings can be summarized as follows. The statistical evidence regarding UIRP is more mixed than previously thought and it depends on the currency pair but not on the horizon. Economically, although our statistics show that UIRP deviations are important, it is crucial to adjust them for small-sample biases. Our results here are of immediate relevance for a growing literature in international economics that makes use of an empirically calibrated "deviation from UIRP", see for example McCallum (1994). In comparison, the statistical evidence against the EHTS is more uniform across countries and horizons. Finally, the deviations from the EHTS are not economically important, indicating that analyzing the effects of policy experiments under the null of the EHTS may be useful.

The remainder of the paper is organized as follows. Section 2 reviews the main hypotheses, UIRP and the EHTS, and how they are related. Section 3 outlines our econometric procedure. Sections 4 and 5 present empirical results from the statistical and the economic perspective. Section 6 focuses on smaller VARs using Japanese data, for which we lack truly long-term zero-coupon rates. Section 7 concludes.

\section{Expectations hypotheses}

\subsection{Uncovered interest rate parity (UIRP)}

UIRP holds at the $n$-period horizon if

$$
\frac{1}{n}\left(E_{t} s_{t+n}-s_{t}\right)=i_{t, n}-i_{t, n}^{*}+\alpha_{n}
$$

where $s_{t}$ is the logarithm of the spot exchange rate (local per foreign currency), $i_{t, n}$ and $i_{t, n}^{*}$ are the time- $t$ continuously compounded domestic and foreign $n$-period interest rate, respectively, and $\alpha_{n}$ is a constant risk premium. All interest rates are expressed in monthly rates.

Denote $\Delta s_{t}=s_{t}-s_{t-1}$. UIRP can be tested with the following regression:

$$
\frac{1}{n} \sum_{i=1}^{n} \Delta s_{t+i}=\alpha_{n}+\beta_{n}^{\text {uirp }}\left(i_{t, n}-i_{t, n}^{*}\right)+\varepsilon_{t, t+n}
$$

Under the null the slope coefficient equals one.

\subsection{Expectations hypotheses of the term structure (EHTS)}

The EHTS holds if the long-term $n$-period interest rate $i_{t, n}$ is an unbiased estimator of the average expected short-term interest rate $i_{t+h, 1}$ during the bond's life plus a constant term premium:

$$
i_{t, n}=\frac{1}{n} \sum_{h=0}^{n-1} E_{t}\left(i_{t+h, 1}\right)+c_{n}
$$


A direct test of this hypothesis (see for example Campbell and Shiller, 1991) is the regression:

$$
\frac{1}{k} \sum_{i=0}^{k-1} i_{t+i m, m}-i_{t, m}=a_{n}+\beta_{n, m}^{\text {ehts }}\left(i_{t, n}-i_{t, m}\right)+u_{t+n-m}
$$

where $k=n / m$ and $m<n$.

Under the EHTS, the slope coefficient in this regression should equal one. ${ }^{1}$

\subsection{UIRP and EHTS}

UIRP at horizon $n$ is implied by UIRP at the short horizon ( $m$ periods, say) and the EHTS at horizon $n$. To see this, assume that the UIRP holds at the shorter-term $m$-period horizon:

$$
\frac{1}{m} \sum_{j=1}^{m} E_{t} \Delta s_{t+j}=\alpha_{m}+i_{t, m}-i_{t, m}^{*}
$$

and that the EHTS holds at the longer-term $n$-period horizon for both domestic and foreign interest rates:

$$
\begin{aligned}
& i_{t, n}=a_{n}+\frac{1}{k} \sum_{j=0}^{k-1} E_{t}\left(i_{t+j m, m}\right) \\
& i_{t, n}^{*}=a_{n}^{*}+\frac{1}{k} \sum_{j=0}^{k-1} E_{t}\left(i_{t+j m, m}^{*}\right)
\end{aligned}
$$

where $k=n / m$. Then UIRP also holds at the $n$-period horizon

$$
\begin{aligned}
i_{t, n}-i_{t, n}^{*} & =a_{n}-a_{n}^{*}+\frac{1}{k} \sum_{j=0}^{k-1} E_{t}\left(i_{t+j m, m}-i_{t+j m, m}^{*}\right) \\
& =\frac{1}{n} \sum_{j=1}^{n} E_{t} \Delta s_{t+j}+a_{n}-a_{n}^{*}-\alpha_{m}
\end{aligned}
$$

As a consequence, although UIRP in the short run, UIRP in the long run and the EHTS at long horizons are three distinct hypotheses, a joint test requires testing only two out of these three hypotheses. Surprisingly, this close relationship between UIRP and the EHTS has been largely ignored in the literature. Campbell and Clarida (1987) and Lewis (1990) jointly studied foreign exchange and term structure returns but they tested latent variable models not the expectations hypotheses. Bekaert and Hodrick (2001) tested both UIRP and the EHTS, but like Campbell and Clarida and Lewis, they only focused on short-horizon Eurocurrency data.

\footnotetext{
${ }^{1}$ Campbell and Shiller (1991) also investigate changes in the long-maturity bond yield over a shorter $m$-period time span. We do not focus on these EHTS-restrictions because they are not directly relevant for the link with UIRP and the empirical implementation suffers from a bias induced by lacking data on the $n-m$-period bond.
} 


\section{Econometric methodology}

\subsection{Regression tests}

The error terms in regressions (2) and (4) are serially correlated when $n, m>1$. Hence OLS standard errors are no longer consistent and a (variant of the) (Hansen and Hodrick, 1980) estimator must be used (see Appendix B).

Regression tests have several disadvantages. First, the Hansen and Hodrick (1980) standard errors have very poor small-sample properties leading to over-rejection. Hodrick (1992) proposes an alternative method (sum the regressors rather than the independent variable) that has much better small-sample properties. Unfortunately, this method is not applicable in this context because the regressor is different for different horizons. We examine below whether the regressions remain useful for our long-horizon tests. Second, the long-horizon regressions have fewer observations than short-horizon regressions, which complicate conducting efficient joint tests across horizons.

\subsection{VAR tests}

An alternative to the simple regression tests that circumvents their disadvantages is to examine UIRP and the EHTS in the context of a VAR on exchange rate changes and interest rates. With a VAR, we can recover (implied) regression slopes from the VAR dynamics and conduct joint Wald tests of UIRP at short and long horizons and the EHTS. Moreover, if we impose the null hypothesis on the VAR dynamics, we can conduct Lagrange multiplier (LM) and distance metric (DM) tests, which have superior size properties compared to the simple Wald test statistic (see Bekaert and Hodrick, 2001). Finally, the dynamics of exchange rates and interest rates under the null and the alternative reveal the economic significance of potential deviations from the null hypotheses.

The variables included in our 5-variable VAR are

$$
y_{t}=\left(\Delta s_{t}, i_{t, 3}, i_{t, 3}^{*}, \mathrm{sp}_{t, 60}, \mathrm{sp}_{t, 60}^{*}\right)^{\prime}
$$

where * again indicates the foreign country, and we take the US as the domestic country. Here $\mathrm{sp}_{t, 60}\left(\mathrm{sp}_{t, 60} *\right)$ is the term spread between the 60-month long rate and the 3-month short rate. We also estimate a cross-country system for Deutsche Mark/Pound rates with Germany functioning as the home country. Furthermore, we estimate two 7-variable VARs where the 12-month or the 36-month term spreads are included for all currency pairs. With these VARs, we can test both long- and shorter-horizon EHTS.

We select the optimal order of the VAR using the BIC criterion, and represent the companion form of the VAR (of order $K$ say) in the usual way as

$$
x_{t+1}=A x_{t}+\xi_{t+1}
$$

with $x_{t+1}=\left(y_{t+1}^{\prime}, y_{t}^{\prime}, \ldots, y_{t+2-K}^{\prime}\right)^{\prime}$, where we suppress the constant term.

Collect the parameters of the $\operatorname{VAR}(A$, the constants and the innovation covariance matrix) in the vector $\theta$. We obtain unconstrained estimates using the generalized methods of moments (GMM; Hansen, 1982) by minimizing the objective function 


$$
g_{T}(\theta)^{\prime} W g_{T}(\theta)
$$

where $W$ is a weighting matrix, and $g_{T}(\theta) \equiv(1 / T) \sum_{t=1}^{T} g\left(x_{t}, \theta\right)$ is the standard set of orthogonality conditions for a VAR system. Hansen (1982) demonstrates that the optimal weighting matrix is the inverse of

$$
\Omega=\sum_{k=-\infty}^{\infty} E\left[g\left(x_{t}, \theta\right) g\left(x_{t-k}, \theta\right)^{\prime}\right]
$$

Let $\Omega_{T}$ be a consistent estimator of $\Omega$ and let the weighting matrix $W$ be optimally chosen as $\Omega_{T}^{-1}$. Denote $G_{T} \equiv \nabla g_{T}(\theta)$. The parameter estimates are asymptotically distributed as

$$
\sqrt{T}\left(\widehat{\theta}-\theta_{0}\right) \rightarrow \mathcal{N}\left(0,\left(G_{T}^{\prime} \Omega_{T} G_{T}\right)^{-1}\right)
$$

The hypotheses of UIRP and the EHTS impose different constraints on the parameters of the VAR. Let $e_{j}$ be an indicator column vector that selects the $j$ th variable in the VAR. Using $E_{t} x_{t+k}=A^{k} x_{t}$ and straightforward algebra, we can show that UIRP at the 3-month horizon implies

$$
\frac{1}{3} e_{1}^{\prime} A\left(I-A^{3}\right)(I-A)^{-1}=e_{2}^{\prime}-e_{3}^{\prime}
$$

while in the 5-variable VAR, UIRP at the 60-month horizon implies

$$
\frac{1}{60} e_{1}^{\prime} A\left(I-A^{60}\right)(I-A)^{-1}=e_{4}^{\prime}-e_{5}^{\prime}+e_{2}^{\prime}-e_{3}^{\prime} .
$$

Similarly the domestic 60-month EHTS imposes the restriction

$$
e_{4}^{\prime}=e_{2}^{\prime}\left[\frac{1}{20}\left(I-A^{60}\right)\left(I-A^{3}\right)^{-1}-I\right] .
$$

Let these constraints be summarized as

$$
\mathrm{H}_{0}: q\left(\theta_{0}\right)=0
$$

Further denote the sample counterpart of $q(\theta)$ by $q_{T}(\theta)$ and its gradient by $Q_{T} \equiv \nabla q_{T}(\theta)$.

The constrained GMM objective function can be written as

$$
L(\theta, \gamma)=-(1 / 2) g_{T}(\theta)^{\prime} \Omega_{T}^{-1} g_{T}(\theta)-q_{T}(\theta)^{\prime} \gamma
$$

where $\gamma$ is the vector of Lagrange multipliers.

Direct maximization of the objective function is difficult as these constraints are highly nonlinear. Instead, we employ the recursive algorithm described in Bekaert and Hodrick (2001). In brief, starting from a consistent estimator $\tilde{\theta}$, which is usually the unconstrained estimator, we iterate on the following two equations derived from Taylor expansions of the first-order conditions to Eq. (19):

$$
\bar{\theta}=\tilde{\theta}-B_{T}^{-1 / 2} M_{T} B_{T}^{-1 / 2} G_{T}^{\prime} \Omega_{T}^{-1} g_{T}(\tilde{\theta})-B_{T}^{-1} Q_{T}^{\prime}\left(Q_{T} B_{T}^{-1} Q_{T}^{\prime}\right)^{-1} q_{T}(\tilde{\theta})
$$




$$
\bar{\gamma}=-\left(Q_{T} B_{T}^{-1} Q_{T}^{\prime}\right)^{-1} Q_{T} B_{T}^{-1} G_{T}^{\prime} \Omega_{T}^{-1} g_{T}(\tilde{\theta})+\left(Q_{T} B_{T}^{-1} Q_{T}^{\prime}\right)^{-1} q_{T}(\tilde{\theta})
$$

where

$$
\begin{aligned}
& B_{T}=G_{T}^{\prime} \Omega_{T}^{-1} G_{T} \\
& M_{T}=I-B_{T}^{-1 / 2} Q_{T}^{\prime}\left(Q_{T} B_{T}^{-1} Q_{T}^{\prime}\right)^{-1} Q_{T} B_{T}^{-1 / 2}
\end{aligned}
$$

We consider three different test statistics of the null hypothesis, the Wald statistic

$$
T q_{T}(\widehat{\theta})^{\prime}\left(Q_{T} B_{T}^{-1} Q_{T}^{\prime}\right)^{-1} q_{T}(\widehat{\theta}) \rightarrow \chi^{2}(k)
$$

the distance metric (DM) statistic

$$
\operatorname{Tg}_{T}(\bar{\theta})^{\prime} \Omega_{T}^{-1} g_{T}(\bar{\theta}) \rightarrow \chi^{2}(k)
$$

and the Lagrange multiplier (LM) statistic

$$
T \bar{\gamma}^{\prime}\left(Q_{T} B_{T}^{-1} Q_{T}^{\prime}\right) \bar{\gamma} \rightarrow \chi^{2}(k)
$$

The DM and LM statistics require estimation under the null. The degrees of freedom $k$ of the $\chi^{2}$ distribution depend on the VAR order.

\subsection{Implied VAR statistics}

Let $\Psi$ be the unconditional variance of $y_{t}$. Together with $A, \Psi$ fully describes the dynamics of exchange rate changes, interest rates and spreads in the VAR. First, we compute implied slope coefficients that correspond to the regression slope coefficients of Section 2. For example, in our 5-variable VAR, the implied 3-month UIRP regression slope is

$$
\beta_{3}^{\text {uirp }}=\frac{1}{3} \frac{e_{1}^{\prime} A\left(I-A^{3}\right)(I-A)^{-1} \Psi\left(e_{2}-e_{3}\right)}{\left(e_{2}^{\prime}-e_{3}^{\prime}\right) \Psi\left(e_{2}-e_{3}\right)},
$$

and the implied EHTS-slope coefficient in Eq. (4) for the domestic 60-month interest rate is

$$
\beta_{60,3}^{\mathrm{ehts}}=\frac{e_{2}^{\prime}\left[\left(I-A^{60}\right)\left(I-A^{3}\right)^{-1} / 20-I\right] \Psi e_{4}}{e_{4}^{\prime} \Psi e_{4}} .
$$

Second, to further characterize the economic significance of deviations from the null hypotheses, we compute three alternative statistics. When UIRP holds, the expected exchange rate change should be perfectly correlated with the interest-rate differential; its variability should equal the variability of the interest differential, and the variability of the foreign risk premium should be zero. Hence we compute

$$
\mathrm{CORR}^{\text {uirp }}=\operatorname{corr}\left(\frac{1}{n} E_{t} \sum_{i=1}^{n} \Delta s_{t+i}, i_{t, n}-i_{t, n}^{*}\right)
$$




$$
\begin{aligned}
\mathrm{VR}^{\text {uirp }} & =\operatorname{var}\left(\frac{1}{n} E_{t} \sum_{i=1}^{n} \Delta s_{t+i}\right) / \operatorname{var}\left(i_{t, n}-i_{t, n}^{*}\right) \\
\mathrm{SD}^{\text {uirp }} & =\left[\operatorname{var}\left(\frac{1}{n} E_{t} \sum_{i=1}^{n} \Delta s_{t+i}+\left(i_{t, n}^{*}-i_{t, n}\right)\right)\right]^{0.5}
\end{aligned}
$$

where the expression between parentheses in Eq. (31) is the foreign exchange risk premium, which we will refer to as $\operatorname{rp}_{t, n}^{\text {uirp }}$.

Analogously, we compute the correlation CORR ${ }^{\text {ehts }}$ between the actual spread and the "theoretical" spread as computed from expected future short rates, $(1 / k) E_{t} \sum_{j=0}^{k-1} i_{t+j m, m}-i_{t, m}$, the corresponding variance ratio $\mathrm{VR}^{\text {ehts }}$ and the standard deviation of their difference $\mathrm{SD}^{\text {ehts }}$. The difference between the theoretical spread and the actual spread can be thought of as the expected excess return to rolling over short-term interest contracts over a period of $n$ months instead of holding the long bond till maturity.

Under the alternative of a time-varying risk premium, it is also interesting to examine Fama's (1984) "excess volatility puzzle". For many economists, a volatility of the risk premium larger than the volatility of expected exchange rate changes would appear excessive. Fama shows that the volatility of the "risk premium" is larger than that of expected changes in the exchange rate as long as the standard UIRP regression coefficient is less than $1 / 2$. Assuming that the investors form their expectation about future exchange rates and interest rates based on current and historical values of our VAR variables only, we can compute the Fama (1984) volatility ratio,

$$
\mathrm{EVR}^{\text {uirp }}=\operatorname{var}\left(\operatorname{rp}_{t, n}^{\text {uirp }}\right) / \operatorname{var}\left(\frac{1}{n} E_{t} \sum_{i=1}^{n} \Delta s_{t+i}\right),
$$

at different horizons from our VAR estimates. ${ }^{2}$ The concept nicely generalizes to deviations from the EHTS. When the ratio of $\mathrm{SD}^{\text {ehts }}$ to the variance of expected spot rate changes is larger than one, this would indicate excess volatility of term structure premiums.

Whereas the excess volatility statistics would be zero under the null of UIRP and the EHTS, they would converge to zero as the horizon increases under the short-term market inefficiency story.

\subsection{Monte Carlo analysis}

Given recent evidence on the poor finite-sample behavior of many test estimators, we conduct a bootstrap analysis of the finite-sample properties of the Wald, LM and DM test statistics, the actual and implied regression slopes and the four economic significance test statistics. Our null model is a biased-corrected version of the constrained VAR with UIRP and the EHTS imposed. Appendix B describes the data generating process and the results in detail. Here, we only summarize our main findings.

\footnotetext{
${ }^{2}$ It can be rewritten as $1+\operatorname{var}\left(i_{t, n}-i_{t, n}^{*}\right) / \operatorname{var}\left((1 / n) E_{t} \sum_{i=1}^{n} \Delta s_{t+i}\right)-2 \operatorname{cov}\left(i_{t, n}-i_{t, n}^{*},(1 / n) E_{t} \sum_{i=1}^{n} \Delta s_{t+i}\right) / \operatorname{var}$ $\left((1 / n) E_{t} \sum_{i=1}^{n} \Delta s_{t+i}\right)$. The second term on the right-hand side is $1 / \mathrm{VR}^{\text {uirp }}$, and the third term equals $2 \times$ $\mathrm{CORR}^{\text {uirp }} /\left(\mathrm{VR}^{\text {uirp }}\right)^{0.5}$.
} 
First, the actual UIRP regression coefficients are downward biased at the 60-month horizon. Together with a dispersion that is typically larger at long horizons, this results in a wider confidence interval for long-horizon slopes. These biases are partly the reason for the very poor small-sample behavior of the $t$-statistics, especially at long horizons. Whereas the small-sample distribution of the implied slope coefficients is similar to that of the OLS counterparts, its small-sample properties are superior: the biases are generally lower and the implied $t$-statistics are much closer to normal.

The EHTS-slope coefficients are upward biased, confirming the Monte Carlo results in Bekaert et al. (1997). The $t$-statistic distribution of the EHTS regression slope is somewhat closer to normal than its UIRP counterpart but it is still severely distorted. Again the VAR implied $t$-stats are much better behaved. Consequently, we do not report direct regression coefficients but focus entirely on the VAR results. ${ }^{3}$

Second, generalizing the findings in Bekaert and Hodrick (2001), the LM test statistic has little size distortion and its finite-sample distribution is well-approximated by the asymptotic $\chi^{2}$ distribution. Hence, we only use the LM test for our VAR-based tests. The Wald statistic has the worst size distortion and its use invariably leads to over-rejection.

Third, the examination of the four economic significance statistics reveals important biases and wide finite-sample distributions. For example, the correlation and variance ratio statistics, also used by Campbell and Shiller (1991) in a study on the EHTS in the US, show downward and upward bias, respectively. The bias is least severe for statistics involving the theoretical spread, exactly the hypotheses Campbell and Shiller (1991) focused on. Not surprisingly, the standard deviation of the risk premium is an upwardly biased statistic but the bias is economically large and is most severe for short-horizon UIRP premiums. This foreign exchange risk premium is exactly the variable that is a critical input in a number of recent analysis, such as McCallum (1994). The Fama excess volatility ratio statistic is also upwardly biased, with the bias less severe at shorter horizons and for the term structure tests.

In reporting these statistics below, we always add the Monte Carlo mean and a [2.5\%, 97.5\%] confidence interval based on the Monte Carlo analysis.

\section{Statistical evidence on the expectations hypotheses}

Table 1 reports the LM test results for our base 5-variable VAR system with 3-month and 60month interest rate data and the two 7-variable systems. The latter systems add the intermediate maturity to both "short" and "long" horizon tests in UIRP. Therefore, Table 1 contains joint tests across all possible combinations of maturities except those involving both 12-month and 36-month data.

We find no evidence against UIRP at either the 3-month or the 60-month horizon in the USD-DEM system at the 5\% significance level (See Panel A). For the USD-GBP system, the results are more mixed. The LM test marginally fails to reject the null at the 3-month and the 60-month horizons separately in the 5-variable VAR. However, in the 7-variable systems we reject UIRP at the 5\% level for short horizons but fail to reject at long horizons. Generally, the $p$-values are rather low. Hence, there is only weak evidence that the UIRP holds up

\footnotetext{
${ }^{3}$ Direct regression results are available upon request. We find that one reason for Chinn and Meredith's (2004) claim that UIRP holds better at longer horizons is simply sample choice. When we restrict our sample to start only in 1980, the slope coefficients are closer to the ones Chinn and Meredith find.
} 
Table 1

VAR-based expectations hypotheses tests

\begin{tabular}{|c|c|c|c|c|c|c|c|c|c|}
\hline & \multicolumn{3}{|l|}{ USD-DEM } & \multicolumn{3}{|l|}{ USD-GBP } & \multicolumn{3}{|l|}{ DEM-GBP } \\
\hline & $3 / 36 / 60 \mathrm{~m}$ & $3 / 12 / 60 \mathrm{~m}$ & $3 / 60 \mathrm{~m}$ & $3 / 36 / 60 \mathrm{~m}$ & $3 / 12 / 60 \mathrm{~m}$ & $3 / 60 \mathrm{~m}$ & $3 / 36 / 60 \mathrm{~m}$ & $3 / 12 / 60 \mathrm{~m}$ & $3 / 60 \mathrm{~m}$ \\
\hline \multicolumn{10}{|c|}{ Panel A: UIRP tests } \\
\hline UIRP short & $15.9242(0.3180)$ & $18.2930(0.1938)$ & $4.6712(0.4573)$ & $33.3951(0.0025)$ & $26.9761(0.0194)$ & $9.4966(0.0908)$ & $31.7254(0.0044)$ & $36.3987(0.0009)$ & $14.5589(0.0124)$ \\
\hline UIRP long & $17.5211(0.2295)$ & $15.6082(0.3379)$ & $9.7159(0.0837)$ & $23.6114(0.0510)$ & $20.2938(0.1211)$ & $10.6313(0.0592)$ & $39.4183(0.0003)$ & $24.6214(0.0385)$ & $17.0804(0.0043)$ \\
\hline UIRP joint & $23.3671(0.3247)$ & $22.9263(0.3479)$ & $15.2244(0.1241)$ & $-^{\mathrm{b}}\left(-^{\mathrm{b}}\right)$ & $32.9450(0.0468)$ & $18.8895(0.0417)$ & $47.8830(0.0007)$ & $45.9573(0.0013)$ & $19.5211(0.0341)$ \\
\hline \multicolumn{10}{|c|}{ Panel B: EHTS tests } \\
\hline Dm. EHTS short & $17.6799(0.0135)$ & $18.8900(0.0085)$ & $-^{\mathrm{a}}\left(-^{\mathrm{a}}\right)$ & $13.2852(0.0347)$ & $12.9869(0.0724)$ & $-^{\mathrm{a}}\left(-^{\mathrm{a}}\right)$ & $19.9735(0.0056)$ & $25.6445(0.0006)$ & $-^{\mathrm{a}}\left(-^{\mathrm{a}}\right)$ \\
\hline Dm. EHTS long & $15.3414(0.0319)$ & $16.7159(0.0193)$ & $15.3927(0.0088)$ & $15.1061(0.0347)$ & $16.2890(0.0226)$ & $12.6005(0.0274)$ & $14.9291(0.0369)$ & $16.1294(0.0240)$ & $14.7388(0.0115)$ \\
\hline Domestic EHTS & $31.5128(0.0047)$ & $24.8316(0.0363)$ & $-{ }^{\mathrm{a}}\left(-^{\mathrm{a}}\right)$ & $17.3907(0.2360)$ & $-^{\mathrm{b}}\left(-^{\mathrm{b}}\right)$ & $-{ }^{\mathrm{a}}\left(-^{\mathrm{a}}\right)$ & $32.3243(0.0036)$ & $32.7016(0.0032)$ & $-^{\mathrm{a}}\left(-^{\mathrm{a}}\right)$ \\
\hline Fr. EHTS short & $26.1020(0.0005)$ & $22.6457(0.0020)$ & $-^{\mathrm{a}}\left(-^{\mathrm{a}}\right)$ & $15.8615(0.0199)$ & $22.2607(0.0023)$ & $-^{\mathrm{a}}\left(-^{\mathrm{a}}\right)$ & $13.4151(0.0626)$ & $24.8534(0.0008)$ & $-^{\mathrm{a}}\left(-^{\mathrm{a}}\right)$ \\
\hline Fr. EHTS long & $23.4606(0.0014)$ & $20.7820(0.0041)$ & $20.4466(0.0010)$ & $16.6421(0.0199)$ & $13.9282(0.0525)$ & $11.7181(0.0389)$ & $8.3693(0.3012)$ & $6.9398(0.4352)$ & $6.3026(0.2779)$ \\
\hline Foreign EHTS & $34.2008(0.0019)$ & $25.2319(0.0323)$ & $-{ }^{\mathrm{a}}\left(-^{\mathrm{a}}\right)$ & $30.1744(0.0072)$ & $37.4081(0.0006)$ & $-{ }^{\mathrm{a}}\left(-^{\mathrm{a}}\right)$ & $35.6990(0.0012)$ & $-{ }^{\mathrm{b}}\left(-^{\mathrm{b}}\right)$ & $-^{\mathrm{a}}\left(-^{\mathrm{a}}\right)$ \\
\hline EHTS short & $38.8674(0.0004)$ & $69.3878(0.0000)$ & $-^{\mathrm{a}}\left(-^{\mathrm{a}}\right)$ & $24.4973(0.0399)$ & $28.7627(0.0113)$ & $-{ }^{\mathrm{a}}\left(-^{\mathrm{a}}\right)$ & $28.1128(0.0137)$ & $37.4158(0.0006)$ & $-^{\mathrm{a}}\left(-^{\mathrm{a}}\right)$ \\
\hline EHTS long & $36.4519(0.0009)$ & $29.5714(0.0087)$ & $24.5659(0.0062)$ & $26.3432(0.0234)$ & $26.2835(0.0238)$ & $19.1869(0.0380)$ & $22.2286(0.0740)$ & $20.6630(0.1106)$ & $18.6356(0.0451)$ \\
\hline \multicolumn{10}{|c|}{ Panel C: Joint tests } \\
\hline $\begin{array}{l}\text { UIRP short } \\
\text { EHTS short }\end{array}$ & $40.7372(0.0060)$ & $34.4780(0.0322)$ & $-^{\mathrm{a}}\left(-^{\mathrm{a}}\right)$ & $28.6456(0.1228)$ & $33.1392(0.0447)$ & $-^{\mathrm{a}}\left(-^{\mathrm{a}}\right)$ & $38.4449(0.0114)$ & $45.2382(0.0016)$ & $-^{\mathrm{a}}\left(-^{\mathrm{a}}\right)$ \\
\hline $\begin{array}{l}\text { UIRP long } \\
\text { EHTS short }\end{array}$ & $40.9555(0.0057)$ & $51.8688(0.0002)$ & $-^{\mathrm{a}}\left(-^{\mathrm{a}}\right)$ & $29.4433(0.1038)$ & $-{ }^{\mathrm{b}}(0.0652)$ & $-^{\mathrm{a}}\left(-^{\mathrm{a}}\right)$ & $43.2352(0.0029)$ & $49.9648(0.0004)$ & $-^{\mathrm{a}}\left(-^{\mathrm{a}}\right)$ \\
\hline $\begin{array}{l}\text { UIRP short } \\
\text { EHTS long }\end{array}$ & $38.0505(0.0127)$ & $32.5468(0.0515)$ & $26.2010(0.0360)$ & $30.2034(0.0880)$ & $31.5195(0.0654)$ & $23.9954(0.0652)$ & $35.5748(0.0244)$ & $28.2698(0.1327)$ & $24.7116(0.0540)$ \\
\hline
\end{tabular}

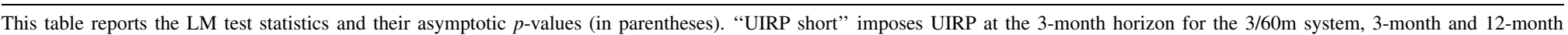

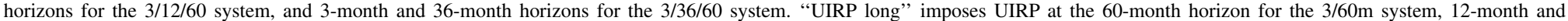

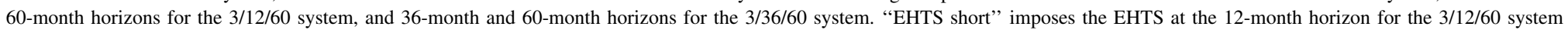

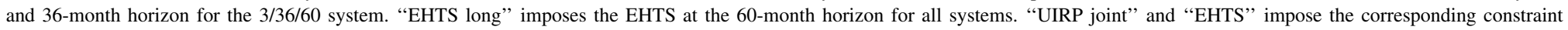
at all horizons. "Dm." ("Fr.") is short for "Domestic" ("Foreign").

a Hypothesis undefined.

${ }^{b}$ Hypothesis not tested because the constrained VAR estimation failed to converge. 
better at long than at short horizons, and the intermediate maturities are key to help reject the hypotheses. The two joint tests across horizons that we could compute both reject at the 5\% level. For the cross-country system of DEM-GBP, the LM test rejects UIRP at all horizons. We conclude that for UIRP, the horizon story seems to be a myth. In some cases, the statistical evidence against UIRP is even stronger at long horizons. Whether one rejects or not depends on the currency pair under investigation. These findings are potentially consistent with a timevarying risk premium explanation, where the variability of the risk premium varies across currencies.

Turning now to Panel B and the EHTS hypothesis, we find that the LM test yields rather uniform evidence against the EH. For the US, we reject the EHTS at all horizons apart from the joint test in the 3/36/60-month USD-GBP system. We always reject the EHTS in Germany at the 5\% level independent of the VAR system. The evidence against the EHTS is the weakest for the GBP, at least in the DEM-GBP system, where we fail to reject the null at long horizons. However, it is likely that the presence of DEM instruments simply reduces the power of the test because in the USD-GBP system, the EHTS in the UK is rejected at both short and long horizons and jointly. The highest $p$-value is $5.25 \%$. When we pool across countries, the EHTS is strongly rejected at short horizons in all systems. At longer horizons, we reject the EHTS at the $1 \%$ level in the USD-DEM system, at the 5\% level in the USD-GBP system, but fail to reject the hypothesis at the 5\% level in the 7-variable DEM-GBP systems. Nevertheless, the $p$-values are rather low.

Panel C contains joint tests of UIRP and the EHTS. Most of interest is the "UIRP Short EHTS Long" hypothesis which not only imposes short-term UIRP and the long-term EHTS but also automatically long-term UIRP (see Section 2). This hypothesis is not equivalent to the joint UIRP hypothesis of Panel A, because that hypothesis did not require the EHTS to hold in both countries. For UIRP to hold both at the short and the long horizons, it must be true that the difference between the term premiums in the two countries is time invariant. This might be the case in the USD-DEM system, where the weaker Panel A test does not reject but the Panel $\mathrm{C}$ test rejects. For the USD-GBP system, the two tests yield similar $p$-values, constituting only marginal evidence against the hypothesis. For the DEM-GBP system, testing the additional restrictions mostly weakens the test, although we still reject the null at the 5\% level in the 3/36/60-month VAR and at close to the 5\% level in the 5-variable VAR. As to the combination of short or long-horizon UIRP with the EHTS at short horizons, we reject these null hypotheses in the USD-DEM and DEM-GBP systems, but the evidence against the hypotheses is weaker in the USD-GBP system.

\section{Economic evidence on the expectations hypotheses}

We now study the five economic significance test statistics: IMPLIED, the implied slope coefficient; CORR, the correlation between the interest-rate differential (term spread) and the expected exchange rate change (expected interest rate changes); VR, the ratio of the variance of expected exchange rate changes (expected interest rate changes) and that of the interest-rate differential (term spread); SD, the standard deviation of the foreign exchange market "risk premium" (term premium); and EVR, the excess volatility ratio. After analyzing the deviations from UIRP and EHTS in Sections 5.1 and 5.2, we consider how imposition of various expectations hypotheses affect certain key impulse responses implied by the VAR. 


\subsection{Uncovered interest rate parity}

\subsubsection{Patterns}

Table 2 contains the results for the three different 5-variable systems (USD-DEM, USDGBP and DEM-GBP) in three panels. First, consider the unconstrained estimation. The correlation statistics inherit the negative sign from the implied slope coefficients and hence expected exchange rate changes and current interest differentials are negatively correlated at both short and long horizons for all three currency pairs. In fact, the correlation is more negative at the 60-month horizon for two of the three currency pairs. The Monte Carlo analysis reveals that correlations are downward biased under the null (see Appendix B). Nevertheless, even the bias-corrected statistics, with the exception of CORR in the USD-DEM system at the 3-month horizon, remain negative. Bias corrected, both CORR and IMPLIED are only more negative for long horizons for the USD-DEM currency pair.

In both the USD-DEM and the USD-GBP systems, VR is above one at the 3-month horizon and below one at the 60-month horizon. In the DEM-GBP system, VR is also above

Table 2

Uncovered interest rate parity at short and long horizons

\begin{tabular}{|c|c|c|c|c|c|c|c|c|c|c|}
\hline & \multicolumn{5}{|l|}{ UIRP $3 \mathrm{~m}$} & \multicolumn{5}{|l|}{ UIRP $60 \mathrm{~m}$} \\
\hline & IMPLIED & CORR & VR & SD & EVR & IMPLIED & CORR & VR & SD & EVR \\
\hline \multicolumn{11}{|c|}{ Panel A: USD-DEM, 3/60 system } \\
\hline Unconstrained & $-0.3741^{*}$ & -0.2674 & 1.9574 & 5.8598 & 1.8931 & $-0.6007 *$ & $-0.6406^{*}$ & 0.8794 & 3.7002 & 3.5034 \\
\hline UIRP long/short & 0.5183 & 0.1289 & 2.8372 & 5.6153 & 1.1994 & 0.6467 & 0.7914 & 0.7203 & 1.2944 & 0.5234 \\
\hline EHTS long & 1.2761 & 0.7550 & 5.3653 & 5.1549 & 0.5345 & 1.2450 & 0.8038 & 4.8294 & 3.1948 & 0.4755 \\
\hline Mean & 1.0173 & 0.6268 & 2.8619 & 4.5864 & 0.8111 & 0.8060 & 0.6639 & 1.6622 & 2.5465 & 1.5791 \\
\hline $2.5 \%$ & -0.3124 & -0.2769 & 0.3517 & 1.7117 & 0.1193 & -0.4410 & -0.5624 & 0.1008 & 0.6771 & 0.0449 \\
\hline $97.5 \%$ & 2.4333 & 0.9767 & 9.0111 & 8.6137 & 3.0964 & 2.0330 & 0.9943 & 6.0438 & 6.4712 & 9.9018 \\
\hline \multicolumn{11}{|c|}{ Panel B: USD-GBP, 3/60 system } \\
\hline Unconstrained & $-2.2587 *$ & $-0.9235^{*}$ & $5.9819 *$ & $8.1009 *$ & 1.9223 & $-0.5729 *$ & $-0.6490 *$ & 0.7794 & 2.8923 & 3.7532 \\
\hline UIRP long/short & 0.8780 & $-0.2554^{*}$ & 2.3351 & 4.8464 & 1.7625 & 0.3981 & 0.6752 & 0.2623 & 1.2774 & 2.1755 \\
\hline EHTS long & $-2.5040^{*}$ & $-0.8274 *$ & $9.3663 *$ & $9.3841 *$ & 1.6475 & $-2.8220 *$ & $-0.8657 *$ & $12.2900 *$ & $7.4407 *$ & 1.5753 \\
\hline Mean & 0.9615 & 0.7512 & 1.7469 & 4.1376 & 0.6431 & 0.7751 & 0.7547 & 1.1766 & 2.3684 & 1.7937 \\
\hline $2.5 \%$ & 0.0111 & 0.0132 & 0.3010 & 1.5763 & 0.0656 & -0.1146 & -0.2282 & 0.0775 & 0.6995 & 0.0354 \\
\hline $97.5 \%$ & 1.8823 & 0.9856 & 4.7697 & 7.6287 & 2.9026 & 1.7779 & 0.9943 & 4.0568 & 5.5961 & 11.5802 \\
\hline \multicolumn{11}{|c|}{ Panel $C: D E M-G B P, 3 / 60$ system } \\
\hline Unconstrained & $-1.1982 *$ & $-0.5598 *$ & 4.5812 & $8.1587^{*}$ & 1.7414 & $-0.7746^{*}$ & $-0.6498 *$ & 1.4210 & 3.0029 & 2.7940 \\
\hline UIRP long/short & 1.0211 & 0.9157 & 1.1359 & 1.2391 & 0.1620 & 0.6229 & 0.6667 & 0.6801 & 1.1482 & 0.8535 \\
\hline EHTS long & $-1.0087^{*}$ & $-0.3738^{*}$ & 3.3494 & $6.9070 *$ & 1.7070 & $-1.3556^{*}$ & $-0.5600^{*}$ & 3.3923 & 3.8289 & 1.9029 \\
\hline Mean & 0.9114 & 0.7030 & 1.7720 & 3.6663 & 0.7310 & 0.6494 & 0.5501 & 1.6070 & 2.4459 & 1.7316 \\
\hline $2.5 \%$ & -0.0955 & -0.1135 & 0.3087 & 1.3946 & 0.0767 & -0.3406 & -0.4308 & 0.1053 & 0.7351 & 0.0828 \\
\hline $97.5 \%$ & 1.8388 & 0.9821 & 4.7012 & 6.7868 & 3.2267 & 1.8880 & 0.9827 & 5.9695 & 6.1345 & 9.0057 \\
\hline
\end{tabular}

This table lists various test statistics for the UIRP regression (2) at the 3 - and the 60-month horizons under different null hypotheses. IMPLIED refers to the implied regression slope coefficients. CORR refers to the correlation statistic. VR refers to the variance ratio statistic. SD refers to the standard deviation of the risk premium. EVR refers to the Fama excess variance ratio statistic. "UIRP long/short" imposes "UIRP long" for "UIRP 3m" regressions and "UIRP short" for "UIRP 60m" regressions. "EHTS long" imposes the EHTS on the foreign exchange regressions. The mean, $2.5 \%$ and $97.5 \%$ critical values provided at the bottom of each panel are based on the bootstrap analysis reported in Appendix B. An asterisk indicates significance at $5 \%$ level using these empirical critical values. 
one at the 60-month horizon. However, the statistic displays an upward bias of about 0.61 so that on a bias-corrected basis, VR is below one even in this system. This indicates that expected exchange rate changes are more variable than the corresponding interest-rate differential in the shorter run, but not necessarily in the long run, even though interest-rate differentials become less variable at longer horizons. Whereas it is tempting to ascribe this large variability in shortterm expected exchange rate changes to irrational factors, these results are potentially consistent with a time-varying risk premium, characterized by a highly persistent component in expected exchange rate changes.

This is confirmed by investigating the standard deviation of the risk premium directly. In all three systems, SD is substantially higher in the short run. Given the decomposition of long-horizon foreign exchange premiums, this must indicate persistent but mean-reverting short-run foreign exchange risk premiums and/or strongly negative correlation between short-run foreign exchange risk premiums and the term premium differential. To see this more clearly, note that the counterpart to Eq. (9) under the alternative of a time-varying risk premium is:

$$
\mathrm{rp}_{t, 60}^{\text {uirp }}=\frac{1}{k} E_{t} \sum_{j=0}^{k-1} \mathrm{rp}_{t+3 j, 3}^{\text {uirp }}+\mathrm{rp}_{t, 60}^{\text {ehts } *}-\mathrm{rp}_{t, 60}^{\text {ehts }}
$$

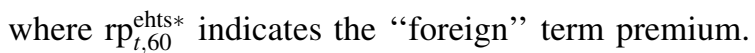

Alternatively, because the risk premium is the sum of expected exchange rate changes and the interest-rate differential, the reduced variability at longer horizons is due to reduced variability in both components. Of course, the VR statistic shows that it is expected exchange rate changes that became relatively less variable.

Given these results, the EVR (excess volatility) patterns are not entirely surprising. Excess volatility comes about because the risk premium embeds the variability of its two components, expected exchange rate changes and interest-rate differentials, which are only weakly or even negatively correlated instead of perfectly correlated.

At the 3-month and the 60-month horizons, respectively, the excess volatility ratio is 1.8931 and 3.5034 for the USD-DEM system, 1.9223 and 3.7533 for the USD-GBP system, and 1.7414 and 2.7939 for the DEM-GBP system, respectively. Our results are stronger than the $\mathrm{U}$ shape in volatility ratios documented in Bauer (2001), but they also support the conclusion that the "excess volatility" phenomenon does not go away in the long run. On the contrary, there is more excess volatility at long horizons, basically because the correlation between expected exchange rate change and interest-rate differences does not become more positive and because the relative variability of expected exchange rate changes decreases. These results are hard to reconcile with a short-term market frictions or market inefficiency story. We conclude that most of the patterns we see are consistent with a time-varying risk premium model with mean-reverting factors.

\subsubsection{Statistical significance}

To judge statistical significance, we rely on the critical values derived from the Monte Carlo analysis described in Appendix B and reported at the bottom of each panel in Table 2.

For the USD-DEM system all statistics could have been generated by a dynamic system which satisfies the expectations hypotheses. However, for the USD-GBP and DEM-GBP systems, only VR, SD and EVR at the long horizons fall comfortably within the $95 \%$ confidence interval. 
The loss of power for the VR, EVR, and especially the SD statistics is interesting in its own right. Empirical estimates of the variability of the risk premium are often chosen as population moments to be matched in general equilibrium models attempting to explain the forward premium anomaly (see for example Bekaert, 1996; Duarte and Stockman, 2005). However, our analysis here shows that this statistic is severely upwardly biased, with the $2.5 \%$ quintile being at least 1.3946 . Similarly, the classic excess volatility results relied on asymptotic statistics without an attempt to correct for small-sample biases. Even under the null, we should expect to see ratios of at least 0.60 at short and 1.5 at long horizons.

Whereas the coefficient patterns described in Section 5.1.1 remain valid when we correct for small-sample bias, small-sample biases appear very important in judging the economic importance of the deviations from UIRP. The implied slope coefficients and correlation statistics reveal that the data remain grossly inconsistent with UIRP, but at the same time, standard statistics considerably exaggerate the deviation from UIRP. Bias-correcting the variability of the risk premium for example, typically leads to standard deviations less than $50 \%$ of the original estimate. ${ }^{4}$

\subsubsection{Dynamics under alternative null hypotheses}

Next we examine how imposing different null hypotheses changes the dynamics of the system. Table 2 shows that imposing UIRP at one horizon almost invariably moves the economic significance statistics closer to their hypothesized values under the null of UIRP at the other horizon. Most strikingly, imposing the UIRP hypothesis in the short run moves the implied slope for the long-run UIRP regression much closer to one, and vice versa. For example, with the USD-DEM data, imposing the UIRP at the 3month horizon brings the implied slope for the 60-month UIRP regression from -0.3741 under the unconstrained VAR up to 0.5183 , while imposing the UIRP at the 60-month horizon brings the implied slope for the 3-month UIRP regression from -0.6007 to 0.6467 . The deviations from UIRP at short and long horizons are clearly highly correlated making it again unlikely that the UIRP is satisfied at the long horizon but not at the short horizon.

The same is not true for the relation between UIRP and the EHTS. Imposing the EHTS has very different effects depending on the currency pair and the statistic. Of main interest here is the behavior of SD. The variance of the longer-horizon UIRP premium can be decomposed into the variance of the short-horizon UIRP premiums, the variance of the difference in domestic and foreign EHTS term premiums, and the covariance of these two terms. We can examine their relative importance by imposing either short-horizon UIRP or the EHTS. Comparing SD(rp) computed under the unconstrained VAR, the constrained VAR under 3-month UIRP, and the constrained VAR under the 60-month EHTS across countries we find that imposing 3-month UIRP decreases the volatility of the long-horizon foreign exchange risk premium much more than does imposing the 60-month EHTS hypothesis. In fact, only between $12.24 \%$ (USD-DEM) and $19.51 \%$ (USD-GBP system) of the total variance is accounted for by variation in term premiums (what is left when UIRP short is

\footnotetext{
${ }^{4}$ This being said, the VAR uses a particular limited information set to generate expected values, whereas the true information set is usually larger, potentially inducing more variable UIRP premiums. In Section 5.1.4, we expand the information set and show the estimate for the variability of the risk premium to be very robust.
} 
imposed). Thus longer-term UIRP deviations appear to result primarily from short-term UIRP deviations.

If we assume a persistent risk premium with autocorrelation coefficient $\rho$, then under the null of the EHTS, the relative variability of long- and short-horizon risk premiums is completely governed by $\rho$. In particular:

$$
\mathrm{SD}\left(\mathrm{rp}_{t, 60}^{\text {uirp }}\right)=\frac{1}{20} \frac{1-\rho^{60}}{1-\rho^{3}} \mathrm{SD}\left(\mathrm{rp}_{t, 3}^{\text {uirp }}\right)
$$

From the 3-month and 60-month statistics for $\mathrm{SD}(\mathrm{rp})$, we infer that $\rho$ would be 0.9380 for the USD-DEM risk premium, 0.9715 for the USD-GBP system and 0.9209 for the DEMGBP system.

Imposing the EHTS also has the uniform effect of increasing the variability of expected exchange rate changes relative to interest-rate differentials, especially at long horizons (see the VR statistics). The main mechanism here is the increased persistence of the VAR induced by imposing the EHTS which feeds into expected exchange rate changes.

\subsubsection{Robustness}

It is conceivable that our conclusions are very sensitive to the exact information set used in the VAR, severely reducing their relevance. As indicated before, we also estimate two 7variable VAR systems, for which we also generate all the statistics as in Table 2. Fortunately, the results are remarkably robust. In fact, it is not only the case that the patterns in the statistics are similar across VARs, but the point estimates of the various statistics are very close. To give one example, the volatility of the risk premium, which we would expect to be especially sensitive to the information set, is estimated to be $8.10 \%(2.89 \%)$ at the 3 -month (60month) horizon in the original 5-variable USD-GBP VAR system. In the corresponding 3/12/ 60 -month system, our estimate is $8.07 \%$ (3.15\%) and in the $3 / 36 / 60$-month system, it is $8.45 \%(2.84 \%)$.

We are of course also interested whether the horizon patterns hold up and are uniform across the intermediate maturities. To examine this, Table 3 collects information from the 3 -month and 60-month horizons using the 5-variable VAR but also reports information for the intermediate maturities using the 7-variable VARs. We draw four conclusions:

(1) UIRP deviations are economically important in that exchange rate changes are weak to negatively correlated with interest-rate differentials. Importantly, there is not a clear horizon pattern in these correlations.

(2) The VR statistic (variability of expected exchange rate changes to interest-rate differentials) and the variability of the risk premium decrease monotonically with the horizon whereas the excess volatility ratio EVR increases monotonically with the horizon. Excess volatility is not a short-run phenomenon!

(3) When we bias-correct the statistics, the results are mostly (but not always) preserved, but generally become much less pronounced. The economic deviations of UIRP are less strong than previously thought.

(4) Imposing UIRP at different horizons than the horizon under examination on the VAR dynamics with one exception moves all statistics closer to their hypothesized values under the null, sometimes dramatically so. For example, the implied slopes and correlation statistics in the DEM-GBP system all become very close to one. 
Table 3

Uncovered interest rate parity over various horizons

\begin{tabular}{|c|c|c|c|c|c|c|}
\hline & & IMPLIED & CORR & VR & SD & EVR \\
\hline \multicolumn{7}{|c|}{ Panel A: USD-DEM } \\
\hline \multirow[t]{3}{*}{ UIRP 3m } & Unconstrained & -0.3741 & -0.2674 & 1.9574 & 5.8598 & 1.8931 \\
\hline & Bias corrected & -0.3914 & 0.1058 & 0.0955 & 1.2734 & 1.0820 \\
\hline & UIRP long & 0.5183 & 0.1289 & 2.8372 & 5.6153 & 1.1994 \\
\hline \multirow[t]{3}{*}{ UIRP $12 \mathrm{~m}$} & Unconstrained & -0.5643 & -0.3802 & 2.2026 & 5.3879 & 1.9664 \\
\hline & Bias corrected & -0.4580 & -0.0358 & 1.2291 & 1.5427 & 1.1242 \\
\hline & UIRP $3 \& 60$ & 1.3763 & 0.8826 & 1.3029 & 1.3895 & 0.2211 \\
\hline \multirow[t]{3}{*}{ UIRP $36 \mathrm{~m}$} & Unconstrained & -0.5307 & -0.4485 & 1.4000 & 4.3022 & 2.4724 \\
\hline & Bias corrected & -0.3328 & 0.0272 & -0.1814 & 1.5329 & 1.2841 \\
\hline & UIRP $3 \& 60$ & 1.2834 & 0.9624 & 1.2430 & 0.7205 & 0.0781 \\
\hline \multirow[t]{3}{*}{ UIRP $60 \mathrm{~m}$} & Unconstrained & -0.6007 & -0.6406 & 0.8794 & 3.7002 & 3.5034 \\
\hline & Bias corrected & -0.4067 & -0.3045 & 0.2172 & 1.1537 & 1.9243 \\
\hline & UIRP short & 0.6467 & 0.7914 & 0.7203 & 1.2944 & 0.5234 \\
\hline \multicolumn{7}{|c|}{ Panel B: USD-GBP } \\
\hline \multirow[t]{3}{*}{ UIRP 3m } & Unconstrained & -2.2587 & -0.9235 & 5.9819 & 8.1009 & 1.9223 \\
\hline & Bias corrected & -2.2202 & -0.6747 & 5.2350 & 3.9633 & 1.2792 \\
\hline & UIRP long & 0.8780 & -0.2554 & 2.3351 & 4.8464 & 1.7625 \\
\hline \multirow[t]{3}{*}{ UIRP $12 \mathrm{~m}$} & Unconstrained & -1.4708 & -0.7084 & 4.3107 & 6.0373 & 1.9144 \\
\hline & Bias corrected & -1.4473 & -0.5788 & 3.9610 & 2.0301 & 1.5296 \\
\hline & UIRP $3 \& 60$ & 1.2694 & 0.8737 & 0.7786 & 1.0225 & 0.3040 \\
\hline \multirow[t]{3}{*}{ UIRP $36 \mathrm{~m}$} & Unconstrained & -0.9523 & -0.7859 & 1.4683 & 3.7369 & 2.9782 \\
\hline & Bias corrected & -0.6997 & -0.4654 & 1.2655 & 1.3390 & 1.2215 \\
\hline & UIRP $3 \& 60$ & 0.8942 & 0.8953 & 1.0249 & 0.8231 & 0.2070 \\
\hline \multirow[t]{3}{*}{ UIRP $60 \mathrm{~m}$} & Unconstrained & -0.5729 & -0.6490 & 0.7794 & 2.8923 & 3.7532 \\
\hline & Bias corrected & -0.3480 & -0.4037 & 0.6028 & 0.5239 & 1.9595 \\
\hline & UIRP short & 0.3981 & 0.6752 & 0.2623 & 1.2774 & 2.1755 \\
\hline \multicolumn{7}{|c|}{ Panel $C: D E M-G B P$} \\
\hline \multirow[t]{3}{*}{ UIRP 3m } & Unconstrained & -1.1982 & -0.5598 & 4.5812 & 8.1587 & 1.7414 \\
\hline & Bias corrected & -1.1096 & -0.2628 & 3.8092 & 4.4924 & 1.0104 \\
\hline & UIRP long & 1.0211 & 0.9157 & 1.1359 & 1.2391 & 0.1620 \\
\hline \multirow[t]{3}{*}{ UIRP $12 \mathrm{~m}$} & Unconstrained & -1.4808 & -0.7060 & 4.3993 & 6.2497 & 1.9005 \\
\hline & Bias corrected & -1.3882 & -0.2907 & 2.9470 & 3.2969 & 1.0492 \\
\hline & UIRP 3\&60 & 1.0901 & 0.9624 & 1.4595 & 0.7916 & 0.0919 \\
\hline \multirow[t]{3}{*}{ UIRP 36m } & Unconstrained & -1.0219 & -0.7104 & 2.0690 & 3.8043 & 2.4711 \\
\hline & Bias corrected & -0.7829 & -0.2507 & 0.9240 & 1.2713 & 1.3154 \\
\hline & UIRP 3\&60 & 1.1717 & 0.9749 & 1.4797 & 0.5528 & 0.0730 \\
\hline \multirow[t]{3}{*}{ UIRP $60 \mathrm{~m}$} & Unconstrained & -0.7746 & -0.6498 & 1.4210 & 3.0029 & 2.7940 \\
\hline & Bias corrected & -0.4240 & -0.1999 & 0.8140 & 1.5570 & 2.0624 \\
\hline & UIRP short & 0.6229 & 0.6667 & 0.6801 & 1.1482 & 0.8535 \\
\hline
\end{tabular}

This table lists various test statistics for the UIRP regressions over various horizons. IMPLIED refers to the implied regression slope coefficients. CORR refers to the correlation statistic. VR refers to the variance ratio statistic. SD refers to the standard deviation of the risk premium. EVR refers to the Fama excess volatility ratio. "UIRP short" imposes the 3-month UIRP hypothesis while "UIRP long" imposes the 60-month UIRP hypothesis. The bias correction is done by adding back the small-sample biases, which are computed by subtracting the empirical mean values from the hypothesized values. The results for the "UIRP $3 \mathrm{~m}$ " and "UIRP $60 \mathrm{~m}$ " come from the $3 / 60$ systems; the results for the "UIRP $12 \mathrm{~m}$ " and "UIRP $36 \mathrm{~m}$ " come from the $3 / 36 / 60$ and the $3 / 12 / 60$ systems, respectively. 


\subsection{Expectations hypotheses of the term structure}

\subsubsection{Patterns and statistical significance}

Table 4 reports the economic statistics for the EHTS in the 5-variable system. We look separately at the USD and the DEM term structure based on the USD-DEM system, and the GBP term structure based on the USD-GBP system. Alternative estimates based on a different VAR system yield qualitatively similar results.

Moving to the statistics in Table 4, both the implied slopes and the correlation coefficients are positive and below one. Except for the US, the correlation coefficient does not appear significantly different from one based on the small-sample critical values. Imposing UIRP has little effect on its value.

Expected future interest rates are more variable than the term spread for the USD and the GBP, but the variance ratio statistic is below one for the DEM. Only the DEM variance ratio statistic is significantly different from one. Imposing UIRP does not lead to a clear pattern in variance ratio changes, with the exception that imposing joint UIRP invariably increases

Table 4

Expectations hypotheses of the term structure

\begin{tabular}{|c|c|c|c|c|c|}
\hline & IMPLIED & CORR & VR & SD & EVR \\
\hline \multicolumn{6}{|c|}{ Panel A: USD EHTS 60m } \\
\hline Unconstrained & 0.7002 & $0.5201 *$ & 1.8119 & 1.6259 & 0.7791 \\
\hline UIRP short & 0.6870 & $0.5531 *$ & 2.3535 & 1.7613 & 0.7038 \\
\hline UIRP long & 0.5932 & $0.5682 *$ & 1.8708 & 1.5701 & 0.7037 \\
\hline UIRP joint & 0.8655 & $0.6140 *$ & 2.1453 & 1.5880 & 0.6277 \\
\hline Mean & 0.9177 & 0.8727 & 1.1319 & 0.9749 & 0.5235 \\
\hline $2.5 \%$ & 0.5226 & 0.6180 & 0.5208 & 0.3732 & 0.0320 \\
\hline $97.5 \%$ & 1.3073 & 0.9899 & 2.0934 & 1.8106 & 0.9251 \\
\hline \multicolumn{6}{|c|}{ Panel B: DEM EHTS 60m } \\
\hline Unconstrained & $0.5154^{*}$ & 0.7911 & $0.4245^{*}$ & 1.1063 & $0.9274 *$ \\
\hline UIRP short & $0.5425^{*}$ & 0.8316 & 0.6745 & 0.9794 & 0.4574 \\
\hline UIRP long & $0.5049 *$ & 0.7904 & 0.7857 & 1.0933 & 0.4894 \\
\hline UIRP joint & 1.3507 & 0.8002 & $2.1667 *$ & $1.5880^{*}$ & 0.3743 \\
\hline Mean & 0.9297 & 0.9281 & 1.0176 & 0.5729 & 0.4235 \\
\hline $2.5 \%$ & 0.5542 & 0.7168 & 0.4842 & 0.1913 & 0.0126 \\
\hline $97.5 \%$ & 1.2330 & 0.9967 & 1.6512 & 1.2079 & 0.8048 \\
\hline \multicolumn{6}{|c|}{ Panel C: GBP EHTS 60m } \\
\hline Unconstrained & 0.9486 & 0.8368 & 1.2852 & 1.0278 & 0.3019 \\
\hline UIRP short & 0.7983 & 0.8046 & 0.9315 & 1.0149 & 0.4061 \\
\hline UIRP long & $0.2623^{*}$ & $0.5872 *$ & 1.0343 & 1.5123 & 0.8121 \\
\hline UIRP joint & $0.3014 *$ & $0.6308 *$ & 2.1078 & 1.8640 & 0.6054 \\
\hline Mean & 1.0256 & 0.9095 & 1.3049 & 1.0924 & 0.3116 \\
\hline $2.5 \%$ & 0.5487 & 0.6894 & 0.4833 & 0.3923 & 0.0235 \\
\hline $97.5 \%$ & 1.4087 & 0.9944 & 2.2812 & 2.2833 & 0.8254 \\
\hline
\end{tabular}

This table lists various test statistics for the 60m EHTS regression (4) under different null hypotheses. USD and DEM (GBP) statistics are from the 3/60-month USD-DEM (USD-GBP) system. IMPLIED refers to the implied regression slope coefficients. CORR refers to the correlation statistic. VR refers to the variance ratio statistic. SD refers to the standard deviation of the risk premium. EVR refers to the Fama excess variance ratio statistic. The $2.5 \%$ and $97.5 \%$ critical values are based on the bootstrap analysis reported in Appendix B. 
the variance ratio. This is primarily caused by the higher persistence of the interest rate in the constrained systems.

The risk premium of rolling over short-term deposits versus holding long-term bonds has a volatility of about $1 \%$ for the DEM and the GBP, and about $1.65 \%$ for the US. These values could have been produced by a system that imposes the EH. Imposing UIRP has little effect on these values, except for increasing them when UIRP is imposed jointly for the DEM and GBP. This is at first somewhat surprising because when UIRP holds at both horizons, the term premium differential across countries must be time invariant. Clearly, this is not accomplished by clamping down the variability of both term premiums. The high variability of the term premiums is the result of the variability of the constrained term premium inheriting some of the variability of the US term premium and the increased persistence of the constrained systems.

We conclude that while the data statistically reject the EHTS, the dynamics of interest rates do not yield patterns that are very different from what we would observe under the EHTS.

\subsubsection{Robustness and horizon effects}

The 7-variable systems can again serve as robustness checks. Moreover, they allow us to analyze the EHTS at both short and long horizons. Our results are very robust across VAR systems. As an example, consider the correlation between the actual spread and the theoretical spread (average expected interest rate changes) for the USD at the 60-month horizon. Table 4 reports a correlation of 0.52 . With the 7 -variable systems, we estimate this correlation with four different information sets: it is 0.51 in the USD-DEM 3/12/60-month system; 0.50 in the USD-DEM 3/36/60-month system; 0.50 in the USD-GBP 3/12/60-month system and 0.49 in the USD-GBP 3/36/60-month system.

Table 5 reports the EHTS results over various horizons. The horizon effects are in many ways opposite to what we found with the UIRP statistics. The correlation between theoretical and actual spread increases with horizon, and is actually negative in the case of the USD at the 12-month horizon (but the negative coefficient would disappear when the downward bias is corrected for). The variance ratio increases with horizon, ${ }^{5}$ as does the variability of the risk premium. The excess volatility ratio decreases with horizon. The strength of the horizon dependence depends on the currency examined, but the results are qualitatively robust across currencies. In other words, the forecasting power of spreads appears rather weak for shortterm interest rates at short horizons but is better for interest rates over longer horizons. The market inefficiency story often told for UIRP seems to fit better for the EHTS. One possible reason for these findings is that monetary policy succeeds in keeping short-term interest rates close to random walks and nearly unforecastable in the short run, but at longer horizons larger economic shocks do drive interest rates, and these are more importantly reflected in long-term interest rates.

When we impose the EHTS at one horizon, the statistics on the other EHTS virtually invariably move closer to their values predicted under the null. This again demonstrates the strong correlation of the EHTS at different horizons, suggesting that a unified explanation based on time-varying risk for example may be possible.

\footnotetext{
${ }^{5}$ Given that the theoretical spread depends on future expected interest rates, this is to be expected when short rates follow a persistent AR(1) process. A derivation of this result is available upon request.
} 
Table 5

Expectations hypotheses of the term structure over various horizons

\begin{tabular}{|c|c|c|c|c|c|c|}
\hline & & IMPLIED & CORR & VR & SD & EVR \\
\hline \multicolumn{7}{|c|}{ Panel A: USD } \\
\hline \multirow[t]{3}{*}{ EHTS $12 \mathrm{~m}$} & Unconstrained & -0.0171 & -0.0243 & 0.4937 & 1.0214 & 3.0948 \\
\hline & Bias corrected & -0.0072 & 0.0010 & 0.4586 & 0.7973 & 3.0406 \\
\hline & EHTS long & 0.2777 & 0.8771 & 0.4985 & 0.4213 & 0.5214 \\
\hline \multirow[t]{3}{*}{ EHTS 36m } & Unconstrained & 0.3994 & 0.3341 & 1.4286 & 1.5373 & 1.1409 \\
\hline & Bias corrected & 0.4056 & 0.4386 & 1.1749 & 0.8965 & 0.9148 \\
\hline & EHTS long & 2.7551 & 0.9522 & 1.1209 & 0.3895 & 0.0934 \\
\hline \multirow[t]{3}{*}{ EHTS 60m } & Unconstrained & 0.6757 & 0.5001 & 1.8256 & 1.6645 & 0.8075 \\
\hline & Bias corrected & 0.6574 & 0.5817 & 1.5738 & 0.7905 & 0.5920 \\
\hline & EHTS short & 0.9820 & 0.9881 & 0.8465 & 0.2306 & 0.0334 \\
\hline \multicolumn{7}{|c|}{ Panel B: DEM } \\
\hline \multirow[t]{3}{*}{ EHTS $12 \mathrm{~m}$} & Unconstrained & 0.1792 & 0.4067 & 0.1941 & 0.8961 & 4.3059 \\
\hline & Bias corrected & 0.1893 & 0.4345 & 0.1513 & 0.7183 & 4.2431 \\
\hline & EHTS long & 0.2554 & 0.7146 & 0.3663 & 0.6939 & 1.3683 \\
\hline \multirow[t]{3}{*}{ EHTS 36m } & Unconstrained & 0.3716 & 0.6726 & 0.3053 & 1.1576 & 1.8408 \\
\hline & Bias corrected & 0.4136 & 0.7217 & 0.2829 & 0.7400 & 1.7218 \\
\hline & EHTS long & 1.0106 & 0.9569 & 0.8119 & 0.4567 & 0.1078 \\
\hline \multirow[t]{3}{*}{ EHTS 60m } & Unconstrained & 0.5081 & 0.7849 & 0.4190 & 1.1578 & 0.9615 \\
\hline & Bias corrected & 0.5519 & 0.8172 & 0.4351 & 0.5487 & 0.8689 \\
\hline & EHTS short & 0.9863 & 0.9703 & 1.1270 & 0.4718 & 0.0594 \\
\hline \multicolumn{7}{|c|}{ Panel $C: G B P$} \\
\hline \multirow[t]{3}{*}{ EHTS $12 \mathrm{~m}$} & Unconstrained & 0.5587 & 0.6354 & 0.7730 & 0.6728 & 0.8482 \\
\hline & Bias corrected & 0.5331 & 0.6718 & 0.6248 & 0.2789 & 0.7600 \\
\hline & EHTS long & 0.2358 & 0.6039 & 1.1480 & 0.7678 & 0.7438 \\
\hline \multirow[t]{3}{*}{ EHTS $36 \mathrm{~m}$} & Unconstrained & 0.9098 & 0.8360 & 1.1845 & 0.8541 & 0.3080 \\
\hline & Bias corrected & 0.9029 & 0.9152 & 0.9653 & 0.1082 & 0.1244 \\
\hline & EHTS long & 0.8193 & 0.9418 & 0.9821 & 0.4803 & 0.1175 \\
\hline \multirow[t]{3}{*}{ EHTS 60m } & Unconstrained & 0.9773 & 0.8300 & 1.3863 & 1.0831 & 0.3115 \\
\hline & Bias corrected & 0.9267 & 0.9253 & 1.0062 & 0.0060 & 0.0729 \\
\hline & EHTS short & 1.1187 & 0.9532 & 1.1348 & 0.5314 & 0.0916 \\
\hline
\end{tabular}

This table lists various test statistics for the EHTS regression (4) over various horizons. IMPLIED refers to the implied regression slope coefficients. CORR refers to the correlation statistic. VR refers to the variance ratio statistic. SD refers to the standard deviation of the risk premium. EVR refers to the Fama excess volatility ratio. "EHTS short" imposes the 36-month ESTH hypothesis while "EHTS long" imposes the 60-month EHTS hypothesis. The bias correction is done by adding back the small-sample biases, which are computed by subtracting the empirical mean values from the hypothesized values. USD and DEM (GBP) statistics come from the USD-DEM (USD-GBP) systems. "EHTS 36m" and "EHTS 60m" ("EHTS 12m") results come from the 3/36/60 (3/12/60 systems) systems.

\section{Expectations hypotheses with Japanese data}

As a final robustness check, we repeat our analysis with Japanese data. Unfortunately, a long-term zero-coupon rate is not available for Japan and to maximize the available sample period, we only use 3-month and 12-month interest rates. We combine the Japanese data with either US, UK or German data, yielding three new VAR systems. Table 6 contains the statistical evidence regarding the expectations hypotheses for the Japanese data. For the JPY, LM tests reveal no differential evidence across the two horizons considered at all. For the USD-JPY pair, UIRP is rejected strongly at $1 \%$ level; for the GBP-JPY pair there is no evidence against UIRP while for the DEM-JPY pair the evidence against UIRP is weak (rejection at the 10\% 
Table 6

VAR-based expectations hypotheses tests for Japan

\begin{tabular}{|c|c|c|c|}
\hline & USD-JPY & GBP-JPY & DEM-JPY \\
\hline & $3 / 12 \mathrm{~m}$ & $3 / 12 \mathrm{~m}$ & $3 / 12 \mathrm{~m}$ \\
\hline \multicolumn{4}{|c|}{ Panel A: UIRP tests } \\
\hline UIRP short & $22.3284(0.0005)$ & $8.6880(0.1223)$ & $10.0757(0.0731)$ \\
\hline UIRP long & $22.8794(0.0004)$ & $8.6265(0.1249)$ & $10.7378(0.0568)$ \\
\hline UIRP joint & $29.0138(0.0012)$ & $15.6731(0.1094)$ & $13.3470(0.2049)$ \\
\hline \multicolumn{4}{|c|}{ Panel B: EHTS tests } \\
\hline Domestic EHTS & $2.5993(0.7615)$ & $4.3164(0.5048)$ & $10.8223(0.0550)$ \\
\hline Foreign EHTS & $4.4857(0.4818)$ & $9.1040(0.1050)$ & $5.1592(0.3968)$ \\
\hline EHTS joint & $8.4207(0.5878)$ & $12.1762(0.2734)$ & $15.2125(0.1245)$ \\
\hline \multicolumn{4}{|c|}{ Panel C: Joint tests } \\
\hline UIRP EHTS & $31.7559(0.0069)$ & $17.2285(0.3054)$ & $24.6885(0.0543)$ \\
\hline
\end{tabular}

This table reports the LM test statistics and their asymptotic $p$-values (in parentheses). "UIRP short" imposes UIRP at the 3-month horizon. "UIRP long" imposes UIRP at the 12-month horizon. "EHTS" imposes the EHTS at the 12month horizon. "UIRP joint" and "EHTS" impose the corresponding constraint at all horizons.

level). Only the VAR with the DEM data seems to yield some marginal evidence against the EHTS holding in Japan. The joint tests mirror the evidence for the UIRP. Clearly, the currency pair remains the main determinant of rejection or non-rejection.

Table 7 reports the economic statistics focusing on the UIRP hypotheses. Given the LM tests, it is not surprising that expected exchange rates and current interest-rate differentials are strongly negatively correlated and the coefficients are statistically significantly different

Table 7

Uncovered interest rate parity at short and long horizons for Japanese data

\begin{tabular}{|c|c|c|c|c|c|c|c|c|c|c|}
\hline & \multicolumn{5}{|l|}{ UIRP $3 \mathrm{~m}$} & \multicolumn{5}{|l|}{ UIRP $12 \mathrm{~m}$} \\
\hline & IMPLIED & CORR & VR & SD & EVR & IMPLIED & CORR & VR & SD & EVR \\
\hline \multicolumn{11}{|c|}{ Panel A: USD-JPY, $3 / 12$ system } \\
\hline Unconstrained & $-3.1890 *$ & $-0.9027 *$ & 12.4809 & $13.1602 *$ & $1.5911^{*}$ & $-3.0611 *$ & $-0.9035^{*}$ & 11.4788 & $11.0106 *$ & $1.6205^{*}$ \\
\hline $\begin{array}{l}\text { UIRP long/ } \\
\text { short }\end{array}$ & 0.8856 & 0.9524 & 1.2169 & 1.0042 & 0.0950 & 1.1032 & 0.9707 & 0.7669 & 0.6597 & 0.0871 \\
\hline EHTS & $-3.3857 *$ & $-0.9338 *$ & 14.6942 & $14.1175^{*}$ & $1.5553^{*}$ & $-3.3693^{*}$ & $-0.9698^{*}$ & 14.4995 & $12.2129 *$ & $1.5783 *$ \\
\hline \multicolumn{11}{|c|}{ Panel B: GBP-JPY, $3 / 12$ system } \\
\hline Unconstrained & $-3.0911 *$ & $-0.6917 *$ & 19.9700 & $9.6392 *$ & $1.3597^{*}$ & $-2.0552 *$ & $-0.6848^{*}$ & 9.0066 & $6.1879 *$ & $1.5674 *$ \\
\hline $\begin{array}{l}\text { UIRP long/ } \\
\text { short }\end{array}$ & 1.2742 & 0.9737 & 1.7110 & 0.7483 & 0.0956 & 0.7417 & 0.9883 & 0.5666 & 0.4622 & 0.1390 \\
\hline EHTS & -2.3097 & $-0.5964 *$ & 21.3837 & $9.7709 *$ & $1.3047 *$ & -2.1738 & $-0.6978^{*}$ & 14.3856 & $7.4892 *$ & $1.4375^{*}$ \\
\hline \multicolumn{11}{|c|}{ Panel $C: D E M-J P Y, 3 / 12$ system } \\
\hline Unconstrained & -1.7370 & $-0.5205^{*}$ & 11.1363 & $8.4995^{*}$ & $1.4017 *$ & -1.7078 & $-0.6633^{*}$ & 6.6284 & $6.1636^{*}$ & $1.6662 *$ \\
\hline $\begin{array}{l}\text { UIRP long/ } \\
\text { short }\end{array}$ & 0.8523 & 0.9613 & 0.9552 & 0.5933 & 0.0796 & 1.1411 & 0.9902 & 1.2187 & 0.3345 & 0.0267 \\
\hline EHTS & -0.6821 & $-0.2893 *$ & 32.2703 & $13.0069 *$ & $1.1328 *$ & -0.2614 & $-0.2695^{*}$ & 23.7559 & $9.7055^{*}$ & $1.1527 *$ \\
\hline
\end{tabular}

This table lists various test statistics for the 3-month and 12-month UIRP regressions (2) under different null hypotheses. IMPLIED refers to the implied regression slope coefficients. CORR refers to the correlation statistic. VR refers to the variance ratio statistic. SD refers to the standard deviation of the risk premium. "UIRP long/short" imposes "UIRP $12 \mathrm{~m}$ " for "UIRP $3 \mathrm{~m}$ " regressions and "UIRP 3m" for "UIRP 12m" regressions. "EHTS" imposes the EHTS on the foreign exchange regressions. An asterisk indicates significance at 5\% level based on the asymptotic distribution. 
Table 8

Expectations hypotheses of the term structure in Japan

\begin{tabular}{|c|c|c|c|c|c|}
\hline & IMPLIED & CORR & VR & SD & EVR \\
\hline \multicolumn{6}{|c|}{ Panel A: USD-JPY } \\
\hline Unconstrained & 0.9555 & 0.9361 & 1.0419 & 0.1823 & 0.1256 \\
\hline UIRP $3 \mathrm{~m}$ & 0.2141 & 0.8692 & 0.4253 & 0.2722 & 0.6856 \\
\hline UIRP $12 \mathrm{~m}$ & 0.2960 & 0.8592 & 0.3839 & 0.2847 & 0.8315 \\
\hline UIRP joint & 0.6234 & 0.9726 & 0.4965 & 0.1788 & 0.2536 \\
\hline \multicolumn{6}{|c|}{ Panel B: $G B P-J P Y$} \\
\hline Unconstrained & 0.8757 & $0.7024 *$ & 1.5542 & $0.4460 *$ & $0.5165^{*}$ \\
\hline UIRP $3 \mathrm{~m}$ & 0.7489 & 0.7228 & 0.9280 & $0.3642 *$ & 0.5770 \\
\hline UIRP $12 \mathrm{~m}$ & 0.7379 & 0.7333 & 0.8560 & $0.3516^{*}$ & 0.5831 \\
\hline UIRP joint & 0.6708 & 0.9514 & 0.4247 & 0.2139 & 0.4349 \\
\hline \multicolumn{6}{|c|}{ Panel C: DEM-JPY } \\
\hline Unconstrained & 0.9439 & 0.9551 & 0.9766 & 0.1488 & 0.0910 \\
\hline UIRP 3m & 0.7908 & 0.9438 & 1.0091 & 0.1676 & 0.1119 \\
\hline UIRP $12 \mathrm{~m}$ & 0.7193 & 0.9314 & 0.9156 & 0.1821 & 0.1454 \\
\hline UIRP joint & 0.8005 & 0.9116 & 2.0276 & 0.3277 & 0.2128 \\
\hline
\end{tabular}

This table lists various test statistics for the 12-month EHTS regression (4) under different null hypotheses. IMPLIED refers to the implied regression slope coefficients. CORR refers to the correlation statistic. VR refers to the variance ratio statistic. SD refers to the standard deviation of the risk premium. An asterisk indicates significance at $5 \%$ level based on the asymptotic distribution.

from one for the USD-JPY system. What is more surprising is that the IMPLIED and CORR statistics are also negative for the GBP-JPY and DEM-JPY currency pairs, with the statistics mostly being significantly different from one. Both the EVR and the SD statistics are economically and significantly different from zero. While this is true for both short and long horizons, we confirm our previous results that both expected exchange rate changes and risk premiums are more variable at short horizons. In all, the economic evidence against UIRP is stronger for the Yen than for the other currencies. Imposing UIRP at either short or long horizons brings the statistics much closer to their values under the null, indicating once again that the deviations from UIRP are not horizon-dependent.

In Table 8, we consider the EHTS for Japan at the 12-month horizon. Consistent with the statistical tests, the economic statistics are all close to one both economically and statistically. When UIRP is imposed, as was often the case in Table 4, the economic statistics mostly decrease.

\section{Conclusions}

Theorists and policy makers have often ignored the deviations from UIRP and the EHTS demonstrated by empirical researchers. The consensus among empirical researchers so far is that the deviations from UIRP are too strong to be matched by theory, ${ }^{6}$ whereas the evidence on the EHTS is decidedly mixed and differs across countries. One reason to motivate a continued use of the hypotheses in certain international theories or policy work may be that irrational

\footnotetext{
${ }^{6}$ There appears to be some evidence that UIRP holds up better in developing countries (Bansal and Dahlquist, 2000) and in the 1990s (Flood and Rose, 2002). However, interest rates in developing countries may be contaminated by country risk premiums. Lothian and $\mathrm{Wu}$ (2003) claim that the evidence against UIRP is weaker when viewed from the perspective of 200 years of US and UK data.
} 
behavior or short-term market frictions cause short-run deviations of the theory but that at longer horizons the theories hold up better. Scattered recent empirical evidence seems to support these contentions. In this paper, we overturn the conventional wisdom along various dimensions.

First, statistically, the evidence against UIRP is quite mixed, as Baillie and Bollerslev (2000) and Bekaert and Hodrick (2001) have pointed out before, and it is currency dependent. We also show that it is not horizon-dependent. Deviations from UIRP seem to be not less severe at long horizons. In fact, Fama's excess volatility ratio is larger at long horizons. Perhaps this is not surprising. Our results are potentially consistent with a time-varying risk premium story for example, where the variability and persistence of risk premiums is different across countries.

Second, although our statistics show that UIRP deviations are economically important, it is critical to adjust them for small-sample biases. Recent theoretical attempts to match the evidence (see Engel, 1996 for a survey; Backus et al., 2001 for a recent example) have invariably focused on population moments estimated from the data. This has led to the recognition that foreign exchange premiums are extremely variable and not a single model of risk has come close to generating such excessive volatility. Our results demonstrate that the small-sample upward bias in this statistic is extreme, a fact that should be taken into account both in theoretical work and in applied work that uses an empirically calibrated foreign exchange risk premium. It may also lead to a re-evaluation of the VAR results on monetary policy's role in exchange rate behavior, where UIRP deviations play an important role (see Eichenbaum and Evans, 1995; Faust and Rogers, 2003).

Third, the statistical evidence against the EHTS is more uniform across countries and horizons than the evidence against UIRP. For the EHTS at short horizons, the presence of long-term interest rates leads to more powerful tests than the tests usually constructed in the literature.

Fourth, economically the deviations from the EHTS are not very important, indicating that analyzing the effects of policy experiments under the null of the EHTS may be useful. Nevertheless, imposing the EHTS does change the VAR dynamics and affects the behavior of foreign exchange premiums.

In a previous version of this article (Bekaert et al., 2002), we also investigated a popular alternative model, the random walk model. If the exchange rate is a random walk, UIRP does not hold. The lack of predictability for exchange rate changes translates into predictable excess returns in the foreign exchange market. So under a time-varying risk premium explanation, the random walk model implies a particular risk premium that is a negative function of the current interest-rate differential. Similarly, a random walk interest rate model implies that the rollover term premium would vary through time as a negative function of the current term spread. In terms of our economic statistics, the random walk model has strong predictions. The IMPLIED and CORR statistics should be exactly zero under the null of a random walk model, the variance ratio should be zero, the SD statistic should reflect the variance of interest-rate differentials and the EVR ratio ought to be infinity. We find that the random walk model fits the data marginally better than the UIRP-EHTS model but fails to match the term structure dynamics in the UK, which appear very consistent with the EHTS. It is possible that central banks play an important role in generating these data dynamics. Clearly, the interest rate smoothing efforts of monetary policy makers induce random-walk-like behavior in interest rates (see e.g. Rudebusch, 1995). But how such behavior interacts with risk premium is unknown. Intriguingly, Mark and Moh (in press) find that UIRP holds at the weekly horizon except during times when central banks engage in foreign exchange intervention. More carefully examining the role of central banks in the deviations from UIRP and the EHTS seems an interesting and important avenue for future research. 


\section{Acknowledgements}

We thank Bob Hodrick and seminar participants at Columbia University for useful comments. Geert Bekaert acknowledges financial support from an NSF grant. The opinions expressed are those of the authors and do not necessarily reflect the views of the Board of Governors of the Federal Reserve System.

\section{Appendix A. Data}

Our data for the US, UK and Germany zero-coupon bond yields is an updated version of the data originally used by Jorion and Mishkin (1991). We thank Philippe Jorion for generously providing us with the data. The Jorion-Mishkin data set consists of monthly observations from 1972:01 through 1991:12 on implied zero-coupon yields with maturities of 3, 12, 24, 36, 48, and 60 months. These yields are constructed from observations on outstanding government bonds. Data from 1990:1 to 1996:9 on zero-coupon bond yields with maturities of 3, 12, 36, and 60 months for the three currencies were obtained from a New York investment bank that wishes to remain anonymous. The exchange rate data are from Datastream.

The Jorion and Mishkin (1991) data set does not include Japanese government bond yields. To our knowledge there is no reliable zero-coupon bond data available on Japanese government bonds. We therefore test all JPY systems using Eurocurrency interest rates for all currencies. Such beginning-of-month 3-month and 12-month Eurocurrency interest rates are obtained from Datastream. When testing the JPY systems, we also use a different set of daily exchange rates obtained from the Board of Governors of the Federal Reserve's public website, from which we create the monthly exchange rate series. The sample period for the JPY systems is from 1978:08 through 1998:12, where the starting date is based on data availability and the ending date is dictated by the introduction of Euro.

\section{Appendix B. Monte Carlo analysis}

We examine the finite-sample properties of various test statistics using a bootstrap analysis.

\section{B.1. The data generating processes (DGP)}

We use various constrained VAR systems as the basis for a DGP. For the 5-variable VAR system, the DGP uses the constrained estimates under the null of 3-month UIRP and the 60month EHTS, that is, all EHTS are imposed. For the 7-variable VAR system, we investigate two different sets of constrained estimates. The first set imposes 3-month UIRP and the intermediate-horizon (12-month or 36-month depending on the system) EHTS, and the second set imposes 3-month UIRP and 60-month EHTS. In all of our experiments, we bootstrap the unconstrained VAR residuals in an i.i.d. fashion. Bekaert and Hodrick (2001) examine a subset of our statistics in an analogous VAR system and show that the small-sample results are robust to an alternative DGP that employs a GARCH model for the residuals.

We correct the constrained estimates for small-sample bias with a procedure also used by Bekaert and Hodrick (2001). We start by bias-correcting the unconstrained VAR parameter estimates. To this end, we use an i.i.d. bootstrap of the unconstrained residuals to generate 50,000 
data sets, each of the same length as the actual data (after throwing out the first 1000 data points to diminish the effect of starting values). For each of the 50,000 samples, we recalculate the unconstrained parameters. We subtract the mean of these estimates from the original unconstrained parameters $\theta_{\mathrm{u}}$ to obtain the small-sample bias. We then add back this bias estimate to the unconstrained estimates $\theta_{\mathrm{u}}$ to obtain the bias-corrected estimates $\tilde{\theta}_{\mathrm{u}}$. To bias-correct the constrained VAR, we use $\tilde{\theta}_{\mathrm{u}}$ to simulate a very long series $(51,000$ observations with the first 1000 observations discarded). We then subject this series to the iterative procedure as described in Section 3.2 to obtain the bias-corrected constrained estimates. Those estimates are what we use in generating the simulation data.

Due to the high persistence of the interest rates, we sometimes ${ }^{7}$ encounter the problem that the bias-corrected constrained estimates have an eigenvalue that is larger than one in absolute value. In such cases we correct the eigenvalues and restore stationarity using a procedure described in Appendix C.

For each DGP, we simulate 25,000 data samples, each consisting of the same number of observations as the actual data. For each data sample, we compute the actual and the implied univariate regression slope coefficients, the economic significance test statistics, and the Wald, LM and DM test statistics for each hypothesis of interest. The remaining analysis in this section focuses on the 5-variable VAR system. The 7-variable VAR systems serve as a robustness check.

\section{B.2. Wald, LM and DM statistics}

The empirical sizes of the Wald, LM and DM test statistics for a 5\% test are shown in Table A1, Panel A. The empirical size is defined as the percentage of Monte Carlo experiments where the test statistics generated under the null exceed the $5 \%$ critical value of a $\chi^{2}$ distribution. While all the three test statistics show some size distortion, the Wald statistic is by far the worst. For example, the empirical size of the Wald statistic for the 60-month EHTS hypothesis is $72.3 \%$ for the USD-DEM system and $77.1 \%$ for the USD-GBP system. The smallest distortion occurs for the "UIRP short" hypothesis in the USD-DEM system, where the empirical size is $11.09 \%$. The DM test also produces empirical sizes larger than 5\% except for the joint test case in the USD-GBP system. However, the upward size distortion is much smaller than for the Wald test. The LM test produces empirical sizes closest to the asymptotic value of 5\%. It is slightly conservative, meaning it will lead to under-rejection in some cases.

Panel B of Table A1 reports the empirical 95\% critical value of the Wald, LM and DM test statistics together with the critical value of the corresponding $\chi^{2}$ distribution. Consistent with Panel A, the LM statistic has empirical critical values that are closest to that of a $\chi^{2}$ distribution.

Overall, our results confirm the findings in Bekaert and Hodrick (2001) that the $\chi^{2}$ distribution is a good approximation to the distribution of the LM test statistic in finite samples. The Wald test widely used in empirical research produces the worst size distortion and invariably leads to serious over-rejection.

Bekaert and Hodrick (2001) also show that all these tests have similar power properties making the LM statistic the obvious test statistic to use in empirical work.

\footnotetext{
${ }^{7}$ This happens with the unconstrained bias-corrected estimates for all two 7-variable USD-DEM and DEM-GBP systems; with the constrained estimates under the null of 3-month UIRP and 60-month EHTS for the 3/12/60-month USD-DEM systems, under the null of 3-month UIRP and 36-month EHTS for the 3/12/60 USD-GBP system, and under both nulls for the 3/36/60-month USD-DEM and USD-GBP systems.
} 
Table A1

Empirical size of test statistics under the null (5\% test)

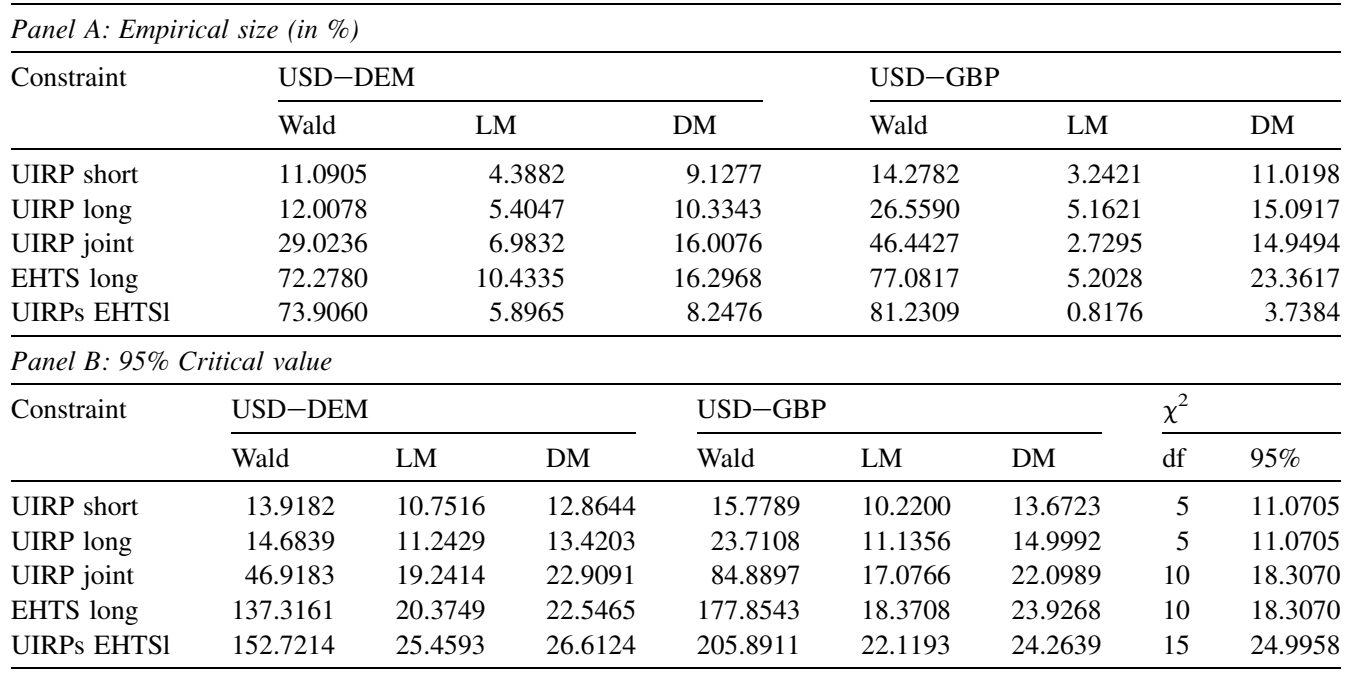

Panel A of this table provides the empirical sizes of various test statistics under different constraints. The empirical size is the percentage of the Monte Carlo replications where the test statistic exceeds the $5 \%$ critical value of a $\chi^{2}$ distribution. Panel B lists the $95 \%$ critical values of various test statistics under different constraints. df refers to the degrees of freedom of the asymptotic $\chi^{2}$ distribution. "UIRPs EHTSl" refers to the joint hypothesis of "UIRP short" and "EHTS long".

\section{B.3. Slope coefficients}

Tables A2-A5 study the small-sample properties of the slope coefficients in various UIRP and EHTS regressions. We look at both direct OLS regression slopes and slope coefficients implied by the VAR systems, and report the mean, standard deviation and the $2.5 \%$ and $97.5 \%$ quantiles. The actual parameter estimates from the data are reported in the last column in each table.

For the direct OLS regression, we employ a "robust" Hansen and Hodrick (1980) estimator. By standard GMM, the asymptotic distribution of the OLS estimator $\theta_{n}=\left(\alpha_{n}, \beta_{n}\right)$ in regression (2) is $\sqrt{T}\left(\widehat{\theta}_{n}-\theta_{n}\right) \sim N(0, \Omega)$, where $\Omega=Z_{0}^{-1} S_{0} Z_{0}^{-1}, Z_{0}=E\left(x_{t} x_{t}^{\prime}\right)$ with $x_{t}^{\prime}=\left(1, i_{t, n}-i_{t, n}^{*}\right)$ and $S_{0}=\sum_{j=-n+1}^{n-1} E\left(w_{t+n} w_{t+n-j}^{\prime}\right)$ with $w_{t+n}=\varepsilon_{t+n} x_{t}$. A consistent estimator of $S_{0}$ is

$$
\widehat{S}_{0}=C(0)+\sum_{j=1}^{n-1}\left[C(j)+C(j)^{\prime}\right]
$$

where

$$
C(j)=\frac{1}{T} \sum_{t=j+1}^{T}\left(w_{t+n} w_{t+n-j}^{\prime}\right)
$$

This is the Hansen and Hodrick (1980) estimator. However, $\widehat{S}_{0}$ may fail to be positive semidefinite. If it is not, we replace it with a Newey and West (1987) estimator with $n$ lags. The estimator $\widehat{\Omega}=\widehat{Z}_{0}^{-1} \widehat{S}_{0}^{-1} \widehat{Z}_{0}$ thus obtained gives rise to our robust Hansen and Hodrick (1980) standard errors. 
Table A2

Empirical distribution of actual regression slopes

\begin{tabular}{|c|c|c|c|c|c|}
\hline & Mean & Std. Dev. & $2.5 \%$ & $97.5 \%$ & Data \\
\hline \multicolumn{6}{|c|}{ Panel A: USD-DEM VAR system } \\
\hline UIRP $3 \mathrm{~m}$ & 1.0254 & 0.6694 & -0.2679 & 2.4044 & -0.3707 \\
\hline UIRP 5y & 0.7314 & 0.7843 & -0.8653 & 2.2410 & -0.2007 \\
\hline EHTS D 5y & 1.0249 & 0.2526 & 0.5304 & 1.5225 & 0.6731 \\
\hline EHTS F 5y & 1.0493 & 0.2107 & 0.6259 & 1.4576 & 1.2836 \\
\hline \multicolumn{6}{|c|}{ Panel B: USD-GBP VAR system } \\
\hline UIRP $3 \mathrm{~m}$ & 0.9598 & 0.4620 & 0.0205 & 1.8675 & -1.9243 \\
\hline UIRP 5y & 0.6836 & 0.6288 & -0.5689 & 1.9102 & 0.3325 \\
\hline EHTS D 5y & 1.0468 & 0.2545 & 0.5507 & 1.5557 & 0.6731 \\
\hline EHTS F 5y & 1.2032 & 0.3040 & 0.5888 & 1.7807 & 1.4183 \\
\hline \multicolumn{6}{|c|}{ Panel $C: D E M-G B P$ VAR system } \\
\hline UIRP $3 \mathrm{~m}$ & 0.9072 & 0.4775 & -0.1060 & 1.8118 & -1.1867 \\
\hline UIRP 5y & 0.5233 & 0.7358 & -0.8714 & 1.9833 & -1.7569 \\
\hline EHTS D 5y & 1.0358 & 0.1969 & 0.6355 & 1.4179 & 1.2836 \\
\hline EHTS F 5y & 1.2154 & 0.2962 & 0.6187 & 1.7853 & 1.4183 \\
\hline
\end{tabular}

This table provides summary statistics for the empirical distributions generated from a constrained VAR with bootstrapped residuals. The summary statistics are the mean, the standard deviation (Std. Dev.) and the $2.5 \%$ and $97.5 \%$ critical values. "Data" refer to the statistics calculated from the actual data. "D" and "F" in the EHTS regressions refer to the first and the second country, respectively, in the name of the VAR.

Focusing first on the slope coefficients in Tables 2 and 3, the bias for the 3-month UIRP regression slope is relatively small, and the difference between the OLS regression slope and the implied slope is also insignificant. At a longer horizon, the 5-year UIRP slope coefficient is significantly downward biased. Bekaert and Hodrick (2001) document downward bias for UIRP

Table A3

Empirical distribution of implied regression slopes

\begin{tabular}{|c|c|c|c|c|c|}
\hline & Mean & Std. Dev. & $2.5 \%$ & $97.5 \%$ & Data \\
\hline \multicolumn{6}{|c|}{ Panel A: USD-DEM VAR system } \\
\hline UIRP $3 \mathrm{~m}$ & 1.0173 & 0.6864 & -0.3124 & 2.4333 & -0.3741 \\
\hline UIRP 5y & 0.8060 & 0.6330 & -0.4410 & 2.0330 & -0.6007 \\
\hline EHTS D 5y & 0.9177 & 0.1980 & 0.5226 & 1.3073 & 0.7002 \\
\hline EHTS F 5y & 0.9297 & 0.1739 & 0.5542 & 1.2330 & 0.5154 \\
\hline \multicolumn{6}{|c|}{ Panel B: USD-GBP VAR system } \\
\hline UIRP $3 \mathrm{~m}$ & 0.9615 & 0.4664 & 0.0111 & 1.8823 & -2.2587 \\
\hline UIRP 5y & 0.7751 & 0.4864 & -0.1146 & 1.7779 & -0.5729 \\
\hline EHTS D 5y & 0.9445 & 0.1760 & 0.6004 & 1.2915 & 0.6331 \\
\hline EHTS F 5y & 1.0256 & 0.2158 & 0.5487 & 1.4087 & 0.9486 \\
\hline \multicolumn{6}{|c|}{ Panel $C: D E M-G B P$ VAR system } \\
\hline UIRP $3 \mathrm{~m}$ & 0.9114 & 0.4882 & -0.0955 & 1.8388 & -1.1982 \\
\hline UIRP 5y & 0.6494 & 0.5812 & -0.3406 & 1.8880 & -0.7746 \\
\hline EHTS D $5 y$ & 0.9440 & 0.1602 & 0.6033 & 1.2354 & 0.5049 \\
\hline EHTS F 5y & 1.0720 & 0.2335 & 0.5493 & 1.4923 & 0.8501 \\
\hline
\end{tabular}

This table provides summary statistics for the empirical distributions generated from a constrained VAR with bootstrapped residuals. The summary statistics are the mean, the standard deviation (Std. Dev.) and the $2.5 \%$ and $97.5 \%$ critical values. "Data" refer to the statistics calculated from the actual data. "D" and "F" in the EHTS regressions refer to the first and the second country, respectively, in the name of the VAR. 
Table A4

Empirical distribution of actual regression slope $t$-statistics

\begin{tabular}{|c|c|c|c|c|c|}
\hline & Mean & Std. Dev. & $2.5 \%$ & $97.5 \%$ & Data \\
\hline \multicolumn{6}{|c|}{ Panel A: USD-DEM VAR system } \\
\hline UIRP $3 \mathrm{~m}$ & 0.0284 & 1.0626 & -2.0791 & 2.1285 & -1.3596 \\
\hline UIRP 5y & -1.0715 & 3.7289 & -9.2093 & 5.2401 & -1.8628 \\
\hline EHTS D 5y & 0.0868 & 1.8418 & -3.6872 & 3.6100 & -1.0790 \\
\hline EHTS F 5y & 0.3960 & 1.8897 & -3.3154 & 4.1289 & 1.4931 \\
\hline \multicolumn{6}{|c|}{ Panel B: USD-GBP VAR system } \\
\hline UIRP $3 \mathrm{~m}$ & -0.0828 & 1.0589 & -2.1659 & 1.9957 & -2.5693 \\
\hline UIRP 5y & -1.5174 & 3.6524 & -9.6211 & 4.2258 & -1.4423 \\
\hline EHTS D 5y & 0.2143 & 1.8197 & -3.4348 & 3.6586 & -1.0790 \\
\hline EHTS F 5y & 1.0898 & 1.8018 & -2.1183 & 4.9895 & 2.5477 \\
\hline \multicolumn{6}{|c|}{ Panel $C: D E M-G B P$ VAR system } \\
\hline UIRP $3 \mathrm{~m}$ & -0.1772 & 1.0582 & -2.2598 & 1.9013 & -2.8760 \\
\hline UIRP 5y & -1.8736 & 3.4463 & -9.7387 & 3.4464 & -6.3525 \\
\hline EHTS D 5y & 0.3340 & 1.9041 & -3.4348 & 4.2182 & 1.4931 \\
\hline EHTS F 5y & 1.1998 & 1.8516 & -2.1198 & 5.2529 & 2.5477 \\
\hline
\end{tabular}

This table provides summary statistics for the empirical distributions generated from a constrained VAR with bootstrapped residuals. The summary statistics are the mean, the standard deviation (Std. Dev.) and the $2.5 \%$ and $97.5 \%$ critical values. "Data" refer to the statistics calculated from the actual data. "D" and "F" in the EHTS regressions refer to the first and the second country, respectively, in the name of the VAR.

regression slopes at the 12-month horizon. Together our results indicate that the downward bias in the UIRP regression gets larger as the horizon increases. This bias-pattern would make it less likely to find coefficients close to 1 at longer horizons than at short horizons. Tauchen (2001) finds upward biases in UIRP regressions but his results are based on a very short sample and a very different DGP that assumes a stationary exchange rate.

Table A5

Empirical distribution of implied regression slope $t$-statistics

\begin{tabular}{|c|c|c|c|c|c|}
\hline & Mean & Std. Dev. & $2.5 \%$ & $97.5 \%$ & Data \\
\hline \multicolumn{6}{|c|}{ Panel A: USD-DEM VAR system } \\
\hline UIRP $3 \mathrm{~m}$ & 0.0153 & 0.9441 & -1.8349 & 1.8883 & -1.2259 \\
\hline UIRP 5y & -0.3434 & 0.9078 & -2.2205 & 1.3218 & -1.5906 \\
\hline EHTS D $5 y$ & -0.5142 & 1.0530 & -2.8194 & 1.2881 & -1.6588 \\
\hline EHTS F 5y & -0.3735 & 0.9806 & -2.4712 & 1.4406 & -1.6187 \\
\hline \multicolumn{6}{|c|}{ Panel B: USD-GBP VAR system } \\
\hline UIRP $3 \mathrm{~m}$ & -0.0781 & 0.9914 & -2.0535 & 1.8674 & -3.0635 \\
\hline UIRP 5y & -0.6322 & 1.0701 & -2.9892 & 1.1208 & -4.5684 \\
\hline EHTS D $5 y$ & -0.4109 & 1.0754 & -2.7658 & 1.4648 & -2.3020 \\
\hline EHTS F 5y & 0.2700 & 0.9480 & -1.4340 & 2.2624 & -0.3383 \\
\hline \multicolumn{6}{|c|}{ Panel $C: D E M-G B P$ VAR system } \\
\hline UIRP $3 \mathrm{~m}$ & -0.1698 & 0.9656 & -2.0980 & 1.7342 & -3.1514 \\
\hline UIRP 5y & -0.8439 & 1.0933 & -3.2680 & 0.9083 & -3.3995 \\
\hline EHTS D 5y & -0.3404 & 0.9882 & -2.4090 & 1.4932 & -1.4375 \\
\hline EHTS F 5y & 0.4537 & 0.9692 & -1.2780 & 2.4323 & -0.7083 \\
\hline
\end{tabular}

This table provides summary statistics for the empirical distributions generated from a constrained VAR with bootstrapped residuals. The summary statistics are the mean, the standard deviation (Std. Dev.) and the $2.5 \%$ and $97.5 \%$ critical values. "Data" refer to the statistics calculated from the actual data. "D" and "F" in the EHTS regressions refer to the first and the second country, respectively, in the name of the VAR. 
As in Bekaert et al. (1997), the EHTS display upward bias. Overall, the absolute values of the biases are somewhat lower with the implied slopes and so are the dispersions. Nevertheless, the slope distributions are quite similar.

Comparing the standard deviations of the slope coefficients, we can see that the dispersion of the UIRP slopes are more widely dispersed than the EHTS regression slopes in Eq. (4). The dispersion of the UIRP slopes is large enough to imply negative $2.5 \%$ quantiles, with the long-horizon critical values lower than the short-horizon ones. The $2.5 \%$ critical values for the term structure regressions are never negative.

As stressed by Li and Maddala (1996) and Bauer (2001), it is important to base inference on "asymptotically pivotal" statistics, that is, statistics with a limit distribution that does not depend on unknown parameters. Hence, we also examine the empirical distributions of the $t$-statistics which satisfy this criterion. Table A4 shows the empirical distributions of the $t$-statistics for direct OLS regression slope coefficients. These $t$-statistics are computed using Hansen and Hodrick (1980) standard errors. Since the UIRP regression slope is downward biased at longer horizons, it is no surprise that we observe on average negative $t$-statistics at longer horizons. At the 5-year horizon, the $2.5 \%$ and $97.5 \%$ empirical critical values for the $t$-statistics of the UIRP slope coefficients are -9.2093 and 5.2401 for the USD-DEM system, and -9.6211 and 4.2258 for the USD-GBP system, respectively, which are remarkably different from their asymptotic critical values \pm 1.96 . These severe distortions make it difficult to use this regression for empirical tests. Whereas the EHTS $t$-statistics are marginally better behaved, their distributions remain very far from the $\mathcal{N}(0,1)$ distribution we expect.

Table A5 shows the empirical distributions of the $t$-statistics for the implied slope coefficients. They are qualitatively similar to the corresponding entries in Table A4 while the biases are smaller and the standard deviation is now close to one, its asymptotic value. This indicates that the implied slope $t$-statistic provides a better test in finite samples than the standard regression $t$-statistic.

\section{B.4. Economic significance statistics}

The small-sample properties of the three economic significance statistics defined in Section 3.2 are documented in Tables A6-A8.

Table A6 presents the empirical distribution of the correlation statistics. While there is a downward bias in all correlation statistics, the downward bias is more severe for the UIRP than for the EHTS regressions. The degree of downward bias in the correlation statistic for the UIRP at the short horizon is comparable to that at the longer horizon. The $2.5 \%$ empirical critical values for UIRP correlation statistics go into the negative territory except in the case of 3-month UIRP for the USD-GBP system.

Table A7 presents the empirical distribution of the variance ratio statistics. All variance ratio statistics are upwardly biased, indicating that on average the variability of expected future asset prices is larger than the variability of current interest-rate differentials. For the UIRP regressions, the upward bias in the variance ratio statistic is larger for the short horizons and economically large. In the USD-DEM system, the average variance ratio varies from 2.862 at the 3-month horizon to 1.662 at the 5-year horizon, while in the USD-GBP system, it decreases from 1.747 at the 3-month horizon to 1.177 at the 5-year horizon. The ratio of the standard deviation of the "theoretical spread" versus actual spread only shows significant bias in the UK.

Table A8 presents the empirical distribution of the standard deviation of foreign exchange and term premiums. The SD statistics are upwardly biased in all cases, which is anticipated 
Table A6

Empirical distribution of the correlation statistic

\begin{tabular}{|c|c|c|c|c|c|}
\hline & Mean & Std. Dev. & $2.5 \%$ & $97.5 \%$ & Data \\
\hline \multicolumn{6}{|c|}{ Panel A: USD-DEM VAR system } \\
\hline UIRP $3 \mathrm{~m}$ & 0.6268 & 0.3316 & -0.2769 & 0.9767 & -0.2674 \\
\hline UIRP 5y & 0.6639 & 0.4074 & -0.5624 & 0.9943 & -0.6406 \\
\hline EHTS D 5y & 0.8727 & 0.1008 & 0.6180 & 0.9899 & 0.5201 \\
\hline EHTS F 5y & 0.9281 & 0.0799 & 0.7168 & 0.9967 & 0.7911 \\
\hline \multicolumn{6}{|c|}{ Panel B: USD-GBP VAR system } \\
\hline UIRP $3 \mathrm{~m}$ & 0.7512 & 0.2559 & 0.0132 & 0.9856 & -0.9235 \\
\hline UIRP 5y & 0.7547 & 0.3140 & -0.2282 & 0.9943 & -0.6490 \\
\hline EHTS D 5y & 0.8927 & 0.0863 & 0.6752 & 0.9928 & 0.4880 \\
\hline EHTS F 5y & 0.9095 & 0.0849 & 0.6894 & 0.9944 & 0.8368 \\
\hline \multicolumn{6}{|c|}{ Panel $C: D E M-G B P$ VAR system } \\
\hline UIRP $3 \mathrm{~m}$ & 0.7030 & 0.2867 & -0.1135 & 0.9821 & -0.5598 \\
\hline UIRP 5y & 0.5501 & 0.3843 & -0.4308 & 0.9827 & -0.6498 \\
\hline EHTS D 5y & 0.9462 & 0.0657 & 0.7689 & 0.9981 & 0.9228 \\
\hline EHTS F 5y & 0.9169 & 0.0812 & 0.7077 & 0.9936 & 0.8457 \\
\hline
\end{tabular}

This table provides summary statistics for the empirical distributions generated from a constrained VAR with bootstrapped residuals. The summary statistics are the mean, the standard deviation (Std. Dev.) and the $2.5 \%$ and $97.5 \%$ critical values. "Data" refer to the statistics calculated from the actual data. "D" and "F" in the EHTS regressions refer to the first and the second country, respectively, in the name of the VAR.

as the statistic is bounded below by zero. The bias is more significant in the UIRP regressions than in the EHTS regressions. For the UIRP regressions, the mean of the SD statistic is larger at shorter horizons. It decreases from 4.586 at the 3-month horizon to 2.547 at the 5-year horizon in the USD-DEM system, and decreases from 4.138 at the 3-month horizon to 2.368 at the 5-year horizon in the USD-GBP system.

Table A7

Empirical distribution of the variance ratio statistic

\begin{tabular}{|c|c|c|c|c|c|}
\hline & Mean & Std. Dev. & $2.5 \%$ & $97.5 \%$ & Data \\
\hline \multicolumn{6}{|c|}{ Panel A: USD-DEM VAR system } \\
\hline UIRP 3m & 2.8619 & 2.5164 & 0.3517 & 9.0111 & 1.9574 \\
\hline UIRP 5y & 1.6622 & 2.2576 & 0.1008 & 6.0438 & 0.8794 \\
\hline EHTS D 5y & 1.1319 & 0.4092 & 0.5208 & 2.0934 & 1.8119 \\
\hline EHTS F 5y & 1.0176 & 0.3109 & 0.4842 & 1.6512 & 0.4245 \\
\hline \multicolumn{6}{|c|}{ Panel B: USD-GBP VAR system } \\
\hline UIRP $3 \mathrm{~m}$ & 1.7469 & 1.2202 & 0.3010 & 4.7697 & 5.9819 \\
\hline UIRP 5y & 1.1766 & 1.2394 & 0.0775 & 4.0568 & 0.7794 \\
\hline EHTS D 5y & 1.1410 & 0.3540 & 0.5862 & 1.9630 & 1.6826 \\
\hline EHTS F 5y & 1.3049 & 0.4578 & 0.4833 & 2.2812 & 1.2852 \\
\hline \multicolumn{6}{|c|}{ Panel $C: D E M-G B P$ VAR system } \\
\hline UIRP $3 \mathrm{~m}$ & 1.7720 & 1.3176 & 0.3087 & 4.7012 & 4.5812 \\
\hline UIRP 5y & 1.6070 & 4.3613 & 0.1053 & 5.9695 & 1.4210 \\
\hline EHTS D 5y & 1.0091 & 0.2862 & 0.5100 & 1.6274 & 0.2993 \\
\hline EHTS F 5y & 1.4047 & 0.5130 & 0.4781 & 2.5022 & 1.0105 \\
\hline
\end{tabular}

This table provides summary statistics for the empirical distributions generated from a constrained VAR with bootstrapped residuals. The summary statistics are the mean, the standard deviation (Std. Dev.) and the $2.5 \%$ and $97.5 \%$ critical values. "Data" refer to the statistics calculated from the actual data. "D" and "F" in the EHTS regressions refer to the first and the second country, respectively, in the name of the VAR. 
Table A8

Empirical distribution of SD(rp)

\begin{tabular}{|c|c|c|c|c|c|}
\hline & Mean & Std. Dev. & $2.5 \%$ & $97.5 \%$ & Data \\
\hline \multicolumn{6}{|c|}{ Panel A: USD-DEM VAR system } \\
\hline UIRP $3 \mathrm{~m}$ & 4.5864 & 2.8221 & 1.7117 & 8.6137 & 5.8598 \\
\hline UIRP 5y & 2.5465 & 3.5902 & 0.6771 & 6.4712 & 3.7002 \\
\hline EHTS D 5y & 0.9749 & 0.8492 & 0.3732 & 1.8106 & 1.6259 \\
\hline EHTS F 5y & 0.5729 & 0.7044 & 0.1913 & 1.2079 & 1.1063 \\
\hline \multicolumn{6}{|c|}{ Panel B: USD-GBP VAR system } \\
\hline UIRP 3m & 4.1376 & 1.7571 & 1.5763 & 7.6287 & 8.1009 \\
\hline UIRP 5y & 2.3684 & 1.6939 & 0.6995 & 5.5961 & 2.8923 \\
\hline EHTS D 5y & 0.8501 & 0.3693 & 0.3104 & 1.5100 & 1.6291 \\
\hline EHTS F 5y & 1.0924 & 0.6782 & 0.3923 & 2.2833 & 1.0278 \\
\hline \multicolumn{6}{|c|}{ Panel C: DEM-GBP VAR system } \\
\hline UIRP 3m & 3.6663 & 1.6920 & 1.3946 & 6.7868 & 8.1587 \\
\hline UIRP $5 y$ & 2.4459 & 2.1057 & 0.7351 & 6.1345 & 3.0029 \\
\hline EHTS D 5y & 0.5832 & 0.3560 & 0.1816 & 1.2544 & 0.9991 \\
\hline EHTS F 5y & 1.2626 & 1.1894 & 0.4468 & 2.8389 & 0.9203 \\
\hline
\end{tabular}

This table provides summary statistics for the empirical distributions generated from a constrained VAR with bootstrapped residuals. The summary statistics are the mean, the standard deviation (Std. Dev.) and the $2.5 \%$ and $97.5 \%$ critical values. "Data" refer to the statistics calculated from the actual data. "D" and "F" in the EHTS regressions refer to the first and the second country, respectively, in the name of the VAR.

Table A9 presents the empirical distribution of the excess variance ratio statistic. The EVR statistic, which should be zero under the null, is upwardly biased for all systems, with the bias mostly worsening with horizon. Going from the 3-month to the 5-year horizon, the bias increases from 0.8111 to 1.5791 in the USD-DEM system, from 0.6431 to 1.7937 in the USD-GBP system, and from 0.7310 to 1.7316 in the DEM-GBP system. The confidence

Table A9

Empirical distribution of Fama excess volatility ratio

\begin{tabular}{|c|c|c|c|c|c|}
\hline & Mean & Std. Dev. & $2.5 \%$ & $97.5 \%$ & Data \\
\hline \multicolumn{6}{|c|}{ Panel A: USD-DEM VAR system } \\
\hline UIRP $3 \mathrm{~m}$ & 0.8111 & 1.2254 & 0.1193 & 3.0964 & 1.8931 \\
\hline UIRP 5y & 1.5791 & 6.0428 & 0.0449 & 9.9018 & 3.5034 \\
\hline EHTS D $5 y$ & 0.5235 & 32.1486 & 0.0320 & 0.9251 & 0.7791 \\
\hline EHTS F 5y & 0.4235 & 32.1635 & 0.0126 & 0.8048 & 0.9274 \\
\hline \multicolumn{6}{|c|}{ Panel B: USD-GBP VAR system } \\
\hline UIRP $3 \mathrm{~m}$ & 0.6431 & 1.1424 & 0.0656 & 2.9026 & 1.9223 \\
\hline UIRP 5y & 1.7937 & 7.6655 & 0.0354 & 11.5802 & 3.7532 \\
\hline EHTS D $5 y$ & 0.2534 & 0.7754 & 0.0243 & 0.7195 & 0.8418 \\
\hline EHTS F 5y & 0.3116 & 8.0481 & 0.0235 & 0.8254 & 0.3019 \\
\hline \multicolumn{6}{|c|}{ Panel C: DEM-GBP VAR system } \\
\hline UIRP $3 \mathrm{~m}$ & 0.7310 & 1.2005 & 0.0767 & 3.2267 & 1.7414 \\
\hline UIRP 5y & 1.7316 & 4.0138 & 0.0828 & 9.0057 & 2.7940 \\
\hline EHTS D 5y & 0.1518 & 0.4610 & 0.0083 & 0.6471 & 0.9675 \\
\hline EHTS F 5y & 0.4137 & 15.2802 & 0.0259 & 0.8194 & 0.3070 \\
\hline
\end{tabular}

This table provides summary statistics for the empirical distributions generated from a constrained VAR with bootstrapped residuals. The summary statistics are the mean, the standard deviation (Std. Dev.) and the $2.5 \%$ and $97.5 \%$ critical values. "Data" refer to the statistics calculated from the actual data. "D" and "F" in the EHTS regressions refer to the first and the second country, respectively, in the name of the VAR. 
intervals are very wide for the UIRP statistics but lower than 1 for the EHTS statistics. The standard deviations of the empirical distribution of this statistic are unreasonably high because of one outlier observation. For example, for the USD-DEM system, dropping the maximum EVR statistic leads to more reasonable standard deviations of $1.1295,4.7629,0.4671$, $0.4488,1.0702$ and 1.3900 .

\section{Appendix C. Eigenvalue correction}

Melino (2001) and Bekaert and Hodrick (2001) show that the various null hypotheses impose restrictions on the eigenvectors of $A$. Consider an eigenvalue decomposition

$$
A=P \Lambda P^{-1}
$$

where $\Lambda$ is the diagonal matrix of eigenvalues and $P$ is the matrix with corresponding eigenvectors. Without loss of generality, we can normalize $P$ so that $P_{1 j}=1 \forall j$ where $P_{i j}$ denotes the $(i, j)$-th entry in the $P$-matrix . To derive the restrictions imposed by 3 -month UIRP, substitute Eq. (C.1) into Eq. (15) and multiply both sides by $P$ from the right-hand side. This gives

$$
\frac{1}{3} \frac{\Lambda_{j}\left(1-\Lambda_{j}^{3}\right)}{1-\Lambda_{j}}=P_{3 j}-P_{2 j}, \quad \forall j
$$

Similarly by substituting Eq. (C.1) into Eq. (17) and simplifying, we obtain the restrictions of the domestic 36-month EHTS on the eigenvectors:

$$
\frac{1}{36} \frac{\Lambda_{j}\left(1-\Lambda_{j}^{36}\right)}{1-\Lambda_{j}}=P_{5 j}-P_{4 j}+P_{3 j}-P_{2 j}, \quad \forall j
$$

When there exist eigenvalues with absolute values larger than one in a constrained system, we replace them with \pm 0.99 and modify the eigenvector matrix $P$ according to the relevant restrictions as discussed above. We can think of the resulting system as the constrained VAR estimates under the additional requirement that the system be stationary.

\section{References}

Backus, D.K., Foresi, S., Telmer, C.I., 2001. Affine term structure models and the forward premium anomaly. Journal of Finance 56 (1), 279-304.

Baillie, R.T., Bollerslev, T., 2000. The forward premium anomaly is not as bad as you think. Journal of International Money and Finance 19 (4), 471-488.

Bansal, R., Dahlquist, M., 2000. The forward premium puzzle: different tales from developed and emerging economies. Journal of International Economics 51 (1), 115-144.

Bauer, G., 2001. The foreign exchange risk premium over the long run. Working Paper.

Bekaert, G., 1996. The time-variation of risk and return in foreign exchange markets: a general equilibrium perspective. Review of Financial Studies 9 (2), 427-470.

Bekaert, G., Hodrick, R.J., 1993. On biases in the measurement of foreign exchange risk premiums. Journal of International Money and Finance 12 (2), 115-138.

Bekaert, G., Hodrick, R.J., 2001. Expectations hypotheses tests. Journal of Finance 56 (4), 1357-1394.

Bekaert, G., Hodrick, R.J., Marshall, D.A., 1997. On biases in tests of the expectations hypothesis of the term structure of interest rates. Journal of Financial Economics 44, 309-348. 
Bekaert, G., Wei, M., Xing, Y., 2002. Uncovered interest rate parity and the term structure. NBER Working Paper 8795.

Bernanke, B.S., Gertler, M., Watson, M., 1997. Systematic monetary policy and the effects of oil price shocks. Brookings Papers on Economic Activity 1997 (1), 91-142.

Campbell, J.Y., Clarida, R.H., 1987. The term structure of Euromarket interest rates: an empirical investigation. Journal of Monetary Economics 19 (1), 25-44.

Campbell, J.Y., Shiller, R.J., 1991. Yield spread and interest rate movements: a bird's eye view. Review of Economic Studies 58 (3), 495-514.

Chaboud, A.P., Wright, J.H., 2005. Uncovered interest parity: it works, but not for long. Journal of International Economics 66 (2), 349-362.

Chinn, M.D., Meredith, G., 2004. Monetary policy and long-horizon uncovered interest parity. IMF staff papers 51 (3), 409-430.

Clarida, R.H., Sarno, L., Taylor, M.P., Valente, G., 2003. The out-of-sample success of term structure models as exchange rate predictors: a step beyond. Journal of International Economics 60 (1), 61-83.

Clarida, R.H., Taylor, M.P., 1997. The term structure of forward exchange premiums and the forecastability of spot exchange rates: correcting the errors. Review of Economics and Statistics 79 (3), 353-361.

Dornbusch, R., 1976. Expectations and exchange rate dynamics. Journal of Political Economy 84 (6), $1161-1176$.

Duarte, M., Stockman, A.C., 2005. Rational speculation and exchange rates. Journal of Monetary Economics 52 (1), 3-29.

Eichenbaum, M., Evans, C.L., 1995. Some empirical evidence on the effects of shocks to monetary policy on exchange rates. Quarterly Journal of Economics 110 (4), 975-1009.

Engel, C., 1996. The forward discount anomaly and the risk premium: a survey of recent evidence. Journal of Empirical Finance 3 (2), 123-192.

Evans, M.D.D., 1998. Real rates, expected inflation, and inflation risk premia. Journal of Finance 53 (1), $187-218$.

Fama, E.F., 1984. Forward and spot exchange rates. Journal of Monetary Economics 14 (3), 319-338.

Faust, J., Rogers, J.H., 2003. Monetary policy's role in exchange rate behavior. Journal of Monetary Economics 50 (7), 1403-1424.

Flood, R.P., Rose, A.K., 2002. Uncovered interest parity in crisis: the interest rate defense in the 1990s. IMF Staff Papers.

Froot, K.A., Thaler, R.H., 1990. Foreign exchange. Journal of Economic Perspectives 4 (3), 179-192.

Green, P., 1992. Is currency trading profitable? Exploiting deviations from uncovered interest rate parity. Financial Analysts Journal 48 (4), 82-86.

Hansen, L.P., 1982. Large sample properties of generalized methods of moments estimators. Econometrica 50 (4), 1029-1054.

Hansen, L.P., Hodrick, R.J., 1980. Forward exchange rates as optimal predictors of future spot rates: an econometric analysis. Journal of Political Economy 88 (5), 829-853.

Hodrick, R.J., 1992. Dividend yields and expected stock returns: alternative procedures for inference and measurement. Review of Financial Studies 5 (3), 357-386.

Jorion, P., Mishkin, F., March 1991. A multicountry comparison of term-structure forecasts at long horizons. Journal of Financial Economics 29 (1), 59-80.

Krugman, P.R., 1991. Target zones and exchange rate dynamics. Quarterly Journal of Economics 106 (3), $669-682$.

Lewis, K.K., 1990. The behavior of Eurocurrency returns across different holding periods and monetary regimes. Journal of Finance 45 (4), 1211-1236.

Li, H., Maddala, G.S., 1996. Bootstrapping time series models. Econometric Reviews 15 (2), 115-158.

Lothian, J.R., Wu, L., 2003. Uncovered interest rate parity over the past two centuries. Working Paper.

Mark, N.C., Moh, Y.-K. Official interventions and the forward premium anomaly. Journal of Empirical Finance, in press.

Mark, N.C., Wu, Y., 1998. Rethinking deviations from uncovered interest parity: the role of covariance risk and noise. The Economic Journal 108 (451), 1686-1706.

McCallum, B.T., 1994. A reconsideration of the uncovered interest parity relationship. Journal of Monetary Economics 33 (1), 105-132.

Melino, A., 2001. An estimation of a rational expectations model of the term structure. Journal of Empirical Finance 8 (5), 639-668.

Newey, W.K., West, K.D., 1987. A simple positive semi-definite, heteroskedasticity and aurocorrelation consistent covariance matrix. Econometrica 51, 1233-1242.

Rudebusch, G.D., 1995. Federal reserve interest rate targeting, rational expectations, and the term structure. Journal of Monetary Economics 35 (2), 245-274.

Tauchen, G., 2001. The bias of tests for a risk premium in forward exchange rates. Journal of Empirical Finance 8 (5), $695-704$. 